\title{
Review of lighting and daylighting control systems
}
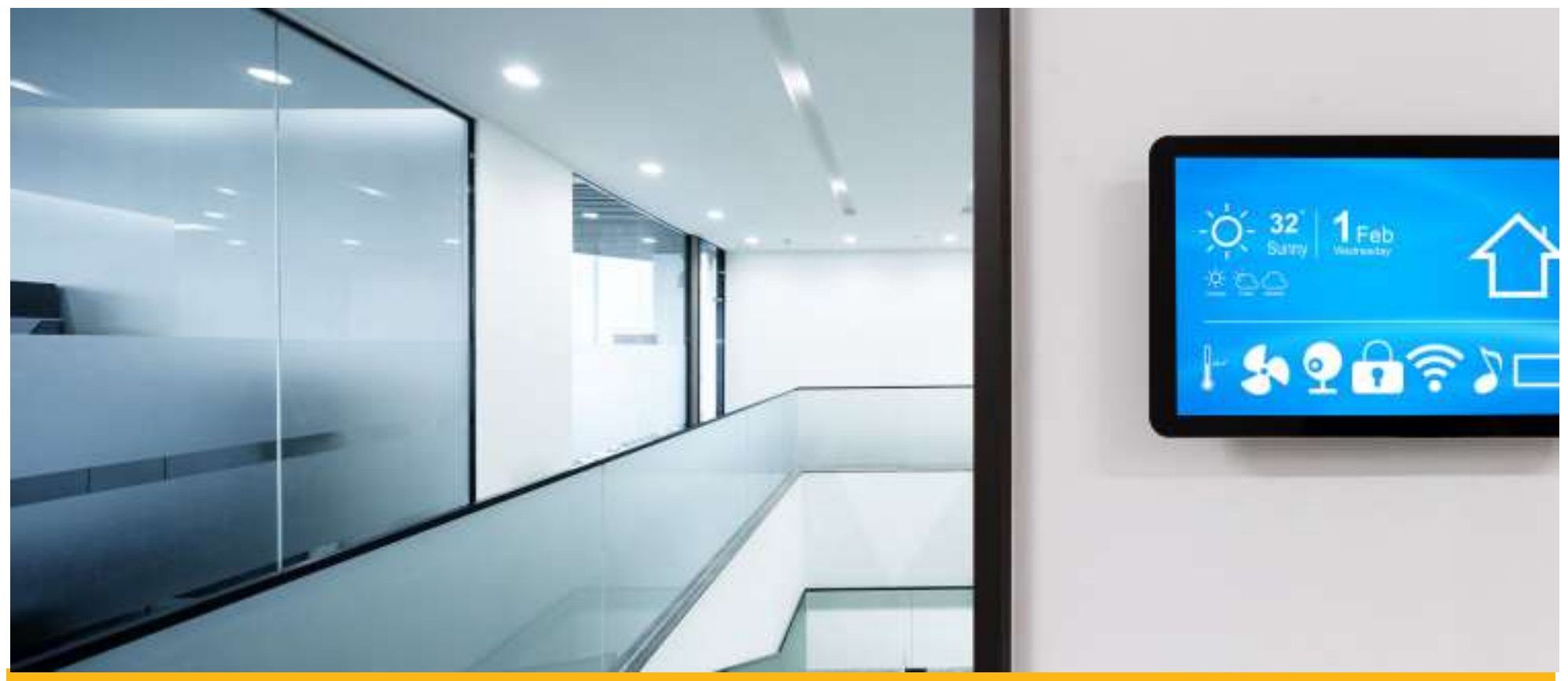

IEA SHC Task 61 / EBC Annex 77: Integrated Solutions for Daylighting and Electric Lighting 


\section{IEA Solar Heating and Cooling Technology Collaboration Programme (IEA SHC)}

The Solar Heating and Cooling Technology Collaboration Programme was founded in 1977 as one of the first multilateral technology initiatives ("Implementing Agreements") of the International Energy Agency. Its mission is "To enhance collective knowledge and application of solar heating and cooling through international collaboration to reach the goal set in the vision of solar thermal energy meeting $50 \%$ of low temperature heating and cooling demand by $2050 . "$

The members of the IEA SHC collaborate on projects (referred to as Tasks) in the field of research, development, demonstration (RD\&D), and test methods for solar thermal energy and solar buildings.

Research topics and the associated Tasks in parenthesis include:

- Solar Space Heating and Water Heating (Tasks 14, 19, 26, 44, 54)

- Solar Cooling (Tasks 25, 38, 48, 53, 65)

- Solar Heat for Industrial or Agricultural Processes (Tasks 29, 33, 49, 62, 64)

- Solar District Heating (Tasks 7, 45, 55)

- Solar Buildings/Architecture/Urban Planning (Tasks 8, 11, 12, 13, 20, 22, 23, 28, 37, 40, 41, 47, 51, 52, 56, 59, 63)

- Solar Thermal \& PV (Tasks 16, 35, 60)

- Daylighting/Lighting (Tasks 21, 31, 50,61)

- Materials/Components for Solar Heating and Cooling (Tasks 2, 3, 6, 10, 18, 27, 39)

- Standards, Certification, and Test Methods (Tasks 14, 24, 34, 43, 57)

- Resource Assessment (Tasks 1, 4, 5, 9, 17, 36, 46)

- Storage of Solar Heat (Tasks 7, 32, 42, 58)

In addition to our Task work, other activities of the IEA SHC include our:

> International Conference on Solar Heating and Cooling for Buildings and Industry

$>$ SHC Solar Academy

$>$ Solar Heat Worldwide annual statics report

$>$ Collaboration with solar thermal trade associations

\section{Country Members}

$\begin{array}{lll}\text { Australia } & \text { France } & \text { South Africa } \\ \text { Austria } & \text { Germany } & \text { Spain } \\ \text { Belgium } & \text { Italy } & \text { Sweden } \\ \text { Canada } & \text { Netherlands } & \text { Switzerland } \\ \text { China } & \text { Norway } & \text { Turkey } \\ \text { Denmark } & \text { Portugal } & \text { United Kingdom } \\ \text { European Commission } & \text { Slovakia } & \end{array}$

\section{Sponsor Members}

European Copper Institute

ECREEE

International Solar Energy Society

RCREEE

CCREEE

RCREEE

EACREEE

SACREEE

For more information on the IEA SHC work, including many free publications, please visit www.iea-shc.org. 


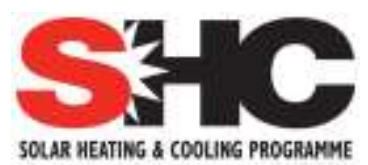

\section{Review of lighting and daylighting control systems}

\section{Editor: Marc Fontoynont}

\section{Authors (in alphabetical order):}

Bruno Bueno Unzeta, Jan de Boer, Ruben Delvaeye, Bertrand Deroisy, Marc Fontoynont, Daniel Neves Pimenta, Per Reinhold, Sophie Stoffer, Robert Weitlaner

\section{1-02-17}

DOI: 10.18777/ieashc-task61-2021-0002

\section{T61.B.2, A Technical Report of Subtask B}

The contents of this report do not necessarily reflect the viewpoints or policies of the International Energy Agency (IEA) or its member countries, the IEA Solar Heating and Cooling Technology Collaboration Programme (SHC TCP) members or the participating researchers. 
AUTHORS (in alphabetical order)

Bruno BUENO UNZETA

Fraunhofer Institute for Solar Energy Systems

ISE

Heidenhofstr. 2,

79110 Freiburg i. Br.

Germany

bruno.bueno@ise.fraunhofer.de

Jan DE BOER

Fraunhofer Institute for Building Physics IBP Nobelstr. 12,

70569 Stuttgart

Germany

jan.deboer@ibp.fraunhofer.de

Ruben DELVAEYE

Belgian Building Research Institute (BBRI)

Avenue Pierre Holoffe, 21,

1342 Limelette

Belgium

ruben.delvaeye@bbri.be

Bertrand DEROISY

Belgian Building Research Institute

Avenue P. Holoffe 21

1342 Limelette

Belgium

bertrand.deroisy@bbri.be

Marc FONTOYNONT

BUILD - Institut for Byggeri, By og Miljø

A.C. Meyers Vænge 15,

2450 København SV

Denmark

mfo@build.aau.dk
Daniel NEVES PIMENTA

Fraunhofer Institute for Building Physics IBP Nobelstr. 12,

70569 Stuttgart

Germany

daniel.neves.pimenta@ibp.fraunhofer.de

Per REINHOLD

Dansk Center for Lys (Danish Lighting Center)

Borupvang 9,

2750 Ballerup

Denmark

pr@centerforlys.dk

Sophie STOFFER

BUILD - Institut for Byggeri, By og Miljø

A.C. Meyers Vænge 15,

2450 København SV

Denmark

asls@build.aau.dk

Robert WEITLANER

HELLA Sonnen- und Wetterschutztechnik

$\mathrm{GmbH}$

9913 Abfaltersbach 125

Austria

robert.weitlaner@hella.info 


\section{KEYWORDS}

Integration, optimization, electric-, artificial-, day-lighting control systems

\section{ACKNOWLEDGEMENTS}

The authors thank their respective funding agencies for supporting their work:

Denmark: ELFORSK (Contract EUDP 64017-05110) 


\section{PREFACE}

Lighting accounts for approximately $15 \%$ of the global electric energy consumption and $5 \%$ of greenhouse gas emissions. Growing economies, higher user demands for quality lighting and rebound effects as a result of low priced and more versatile electric lighting continuously still lead to an absolute increase of lighting energy consumption. More light is used, often less consciously.

Especially the electric lighting market but as well the façade, daylighting und building automation sectors have seen significant technological developments in the past decade. However these sectors still act mainly independent of each other, leaving out big potentials lying in a better technology and market integration. This integration is on the one hand beneficial to providing better user-centred lighting of indoor spaces. On the other hand it can contribute significantly to the reduction of worldwide electricity consumptions and C02-emissions, which is in line with several different governmental energy efficiency and sustainability targets.

IEA SHC Task 61 / EBC Annex 77 "Integrated Solutions for daylighting and electric lighting - From Component to system efficiency" therefore pursues the goal to support and foster the better integration of electric lighting and daylighting systems including lighting controls with a main focus on the non-residential sector. This includes the following activities:

- Review relation between user perspective (needs/acceptance) and energy in the emerging age of "smart and connected lighting" for a relevant repertory of buildings.

- Consolidate findings in use cases and "personas" reflecting the behaviour of typical users.

- Based on a review of specifications concerning lighting quality, non-visual effects as well as ease of design, installation and use, provision of recommendations for energy regulations and building performance certificates.

- Assess and increase robustness of integrated daylight and electric lighting approaches technically, ecologically and economically.

- Demonstrate and verify or reject concepts in lab studies and real use cases based on performance validation protocols.

- Develop integral photometric, user comfort and energy rating models (spectral, hourly) as prenormative work linked to relevant bodies: CIE, CEN, ISO. Initialize standardization.

- Provide decision and design guidelines incorporating virtual reality sessions. Integrate approaches into wide spread lighting design software.

- Combine competencies: Bring companies from electric lighting and façade together in workshops and specific projects. Hereby support allocation of added value of integrated solutions in the market.

To achieve this goal, the work plan of IEA SHC Task 61 / EBC Annex 77 is organized according to the following four main subtasks, which are interconnected by a joint working group:

- Subtask A:

- Subtask B:

- Subtask C:

- Subtask D:

- Joint Working Group:
User perspective and requirements

Integration and optimization of daylight and electric lighting Design support for practitioners (Tools, Standards, Guidelines)

Lab and field study performance tracking

Evaluation tool \& VR Decision Guide

Subtask B focuses on the evolution of the technologies and identifies new opportunities offered by control systems for lighting and daylighting systems, with the objective to improve energy performance as well as improving operation by occupants and facility managers. 


\section{EXECUTIVE SUMMARY}

There is a large number of control systems proposed either by lighting manufacturers or motor manufacturers for shading systems. In addition there are many other solutions proposed by specific manufacturers of Building Management Systems (BMS) or manufacturers of components to be installed in luminaires and switches, as well as in the electric lighting architecture (transformers, gateways to the internet, sensors, etc.). For many consumers -i.e.-the installer, the facility manager, or the final user (building occupant) - this forms a complex and dynamic market environment with high frequent changes, every year or even every month or day. In this report we aim to provide some basic strategic information, showing the status of the supply at the time this report was written (2019-2021). Although the market develops very fast, there are principles of controls which are rather independent of the progress of technology.

The report shows, that opportunities and barriers in lighting control are challenging, but bringing also new options to create valuable contribution to enhance efficient, affordable and comfortable controlling solutions to users, maintainers and planers. Energy conservation cannot be the only objective for the promotion of lighting and daylighting controls, anymore. Tendencies in residential buildings show, that energy benefits need to be associated with other advantages in operation, to make the supply more attractive. As occupants expect to possibly override the system when necessary, the interaction is becoming more and more important. Also the interaction with the installers, the commissioning task and the robustness of the systems should not be underestimated, to raise the acceptance of the building owners, installers and planers. The biggest hurdle, however, is probably the lack of standards and the wide range of solutions from the various sectors.

How can control strategies look like, in such volatile and changing situation? The report provides insights to the principles of controls, which are rather independent to the progress of technology.

By listing and explaining major functions and components of control systems, an overview about the technical possibilities and challenges is given. Different types of daylight and electric lighting control strategies and protocols (wired and wireless) are discussed, to create an understanding of the potentials and barriers of existing and future solutions.

Of course, technologies are facing rapid decay, even though the overview may give helpful insights and help, to better understand the ongoing change and enable to develop an own lighting control strategy. 


\section{Contents}

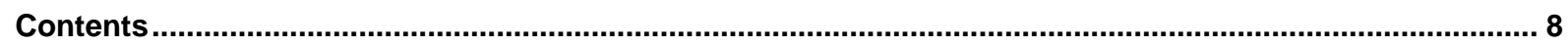

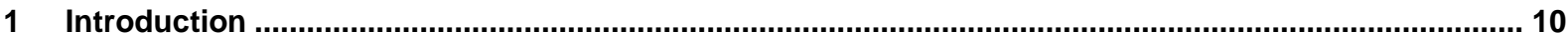

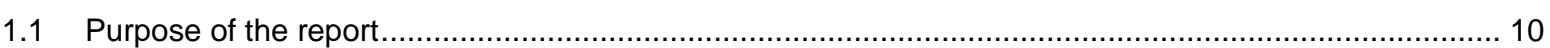

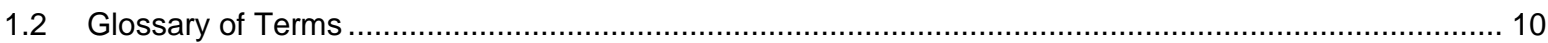

2 Preliminary definitions for integrated solutions for control of daylighting and electric lighting .......... 11

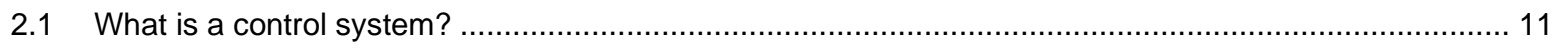

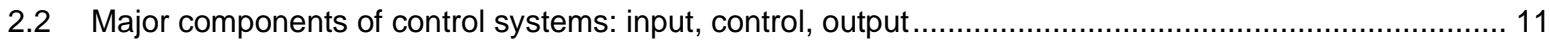

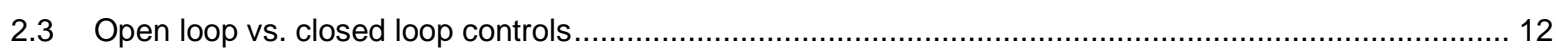

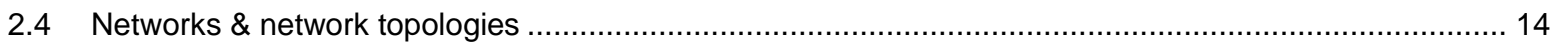

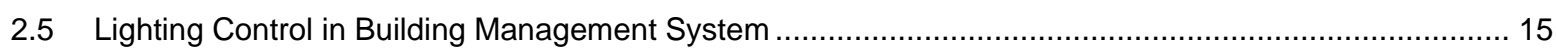

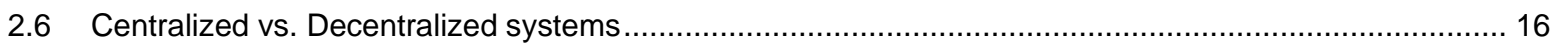

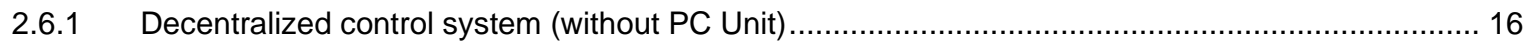

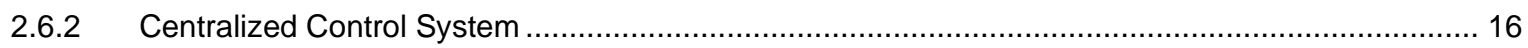

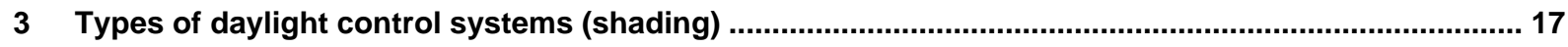

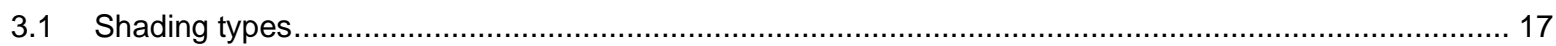

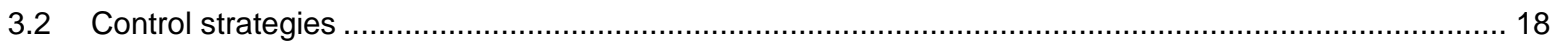

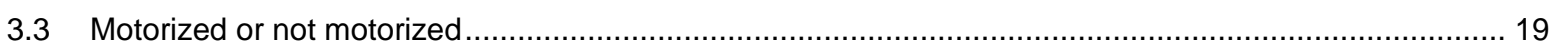

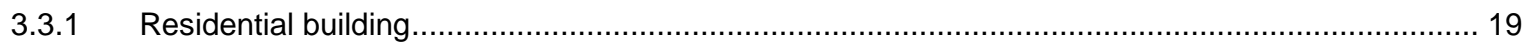

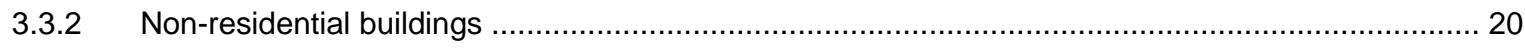

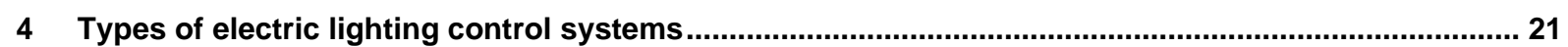

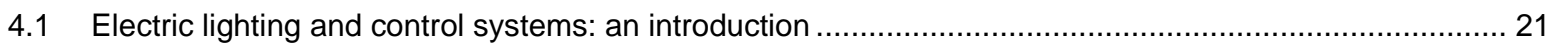

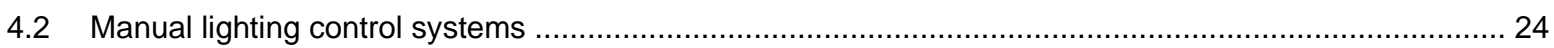

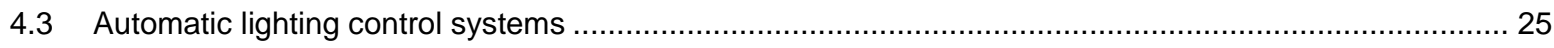

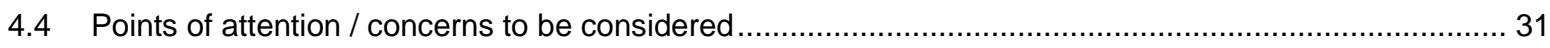

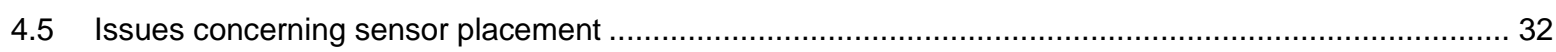

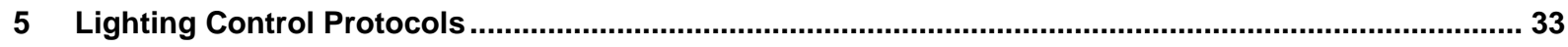

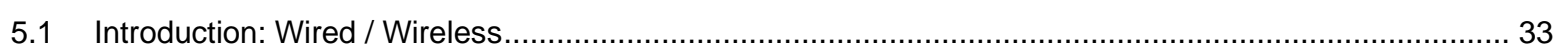

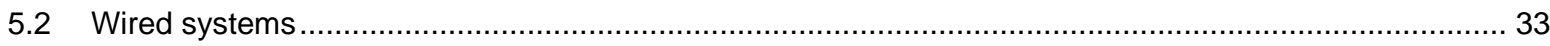

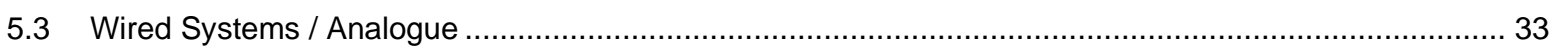

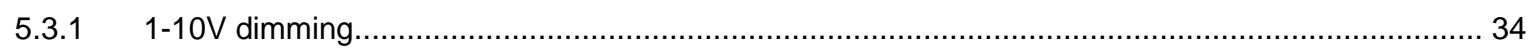

5.3.2 Touch Control Push Button (analogue but can be connected to digital systems) ......................... 34

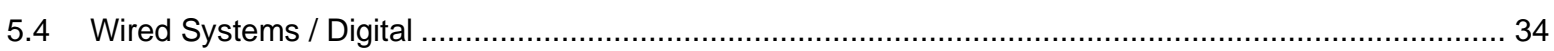

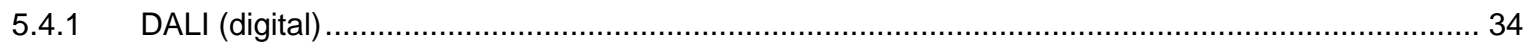

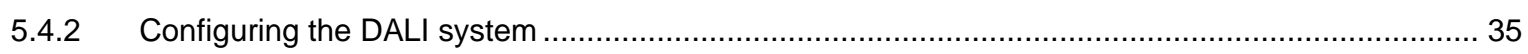

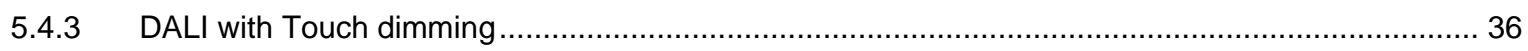

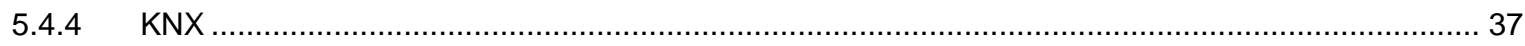

5.4.5 DMX 


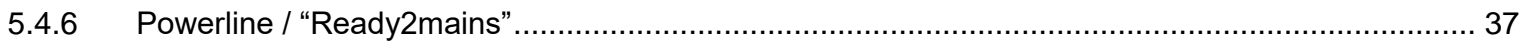

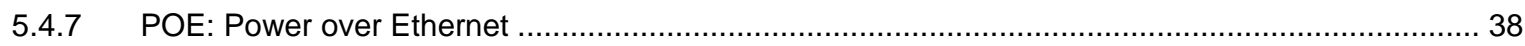

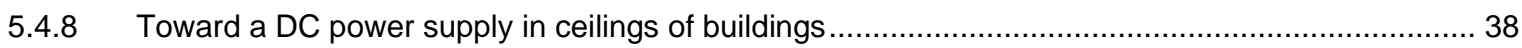

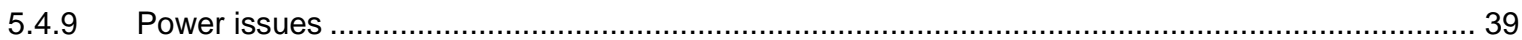

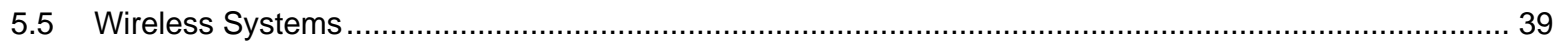

5.5.1 Wireless Lighting Control Systems and various types of wireless protocols .............................. 40

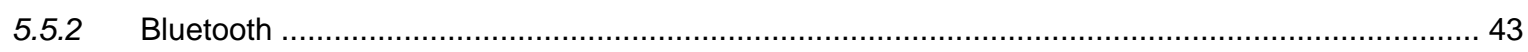

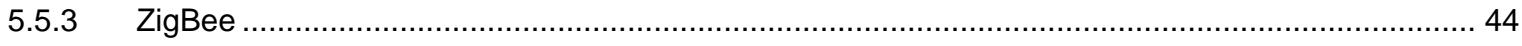

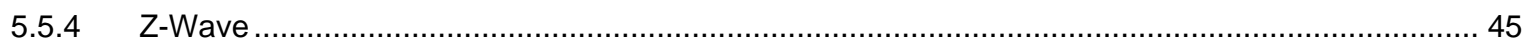

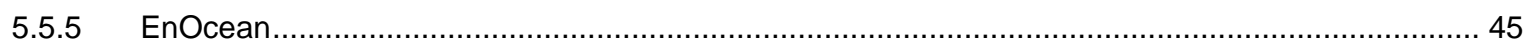

5.6 Pros and cons for the different protocols, from the user perspective......................................... 46

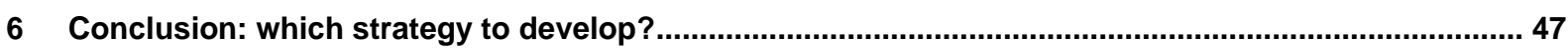




\section{Introduction}

There is a very large number of control systems proposed either by lighting manufacturers or motor manufacturers for shading systems. There are also solutions proposed by specific manufacturers of BMS

(Building Management Systems) or manufacturers of components to be installed in luminaires and switches, as well as in the electric lighting architecture (transformers, gateways to the internet, sensors, etc.). For many consumers -i.e.-the installer, the facility manager, or the final user (building occupant) - this looks like a complex and instable environment, with changes happening every year (or every month or even every day).

\subsection{Purpose of the report}

In this we aim to provide some basic yet strategic information, showing the status of the supply at the time this report was written (2019-2021). It is clear that at the time this has been written, it becomes rapidly obsolete. However, there are principles of controls which are rather independent of the progress of technology.

\subsection{Glossary of Terms}

One of our first tasks was to identify keywords (or attributes) to describe the supply: the way it operates, and the types of components it integrates. Below is a list of terms which are used in this report. The explanation will be described in the text.

- Electric lighting controls

- Dimming capabilities

- Tunable white / colour control

- Open / close protocols

- Wireless / wired

- User interface (User could be the facility manager or the occupant)

- Actuators (component responsible for moving a shading motor for instance)

- Lamp driver (controlling intensity in LED light source, and protecting it)

- Internet of Things (IoT)

- $\quad$ DC / AC power supply for lighting

- $\quad$ Shading controls (for shading systems which could be textile or roller blinds)

- External vs internal shading

- Residential vs commercial buildings

- Closed /open-loop options

- Occupancy sensors

- Daylight sensors

- Location of sensors

- Zoning of lighting installation in a building

- Centralized systems vs decentralized systems

- Flexibility of systems (adaptable to changes of use)

- Glare protection 


\section{Preliminary definitions for integrated solutions for control of daylighting and electric lighting}

\subsection{What is a control system?}

A control system is a set of mechanical or electronic components that, as a whole, regulates the behavior of other devices or systems to achieve a desired result. It creates an output, based on an input signal and logic to translate the input signal into an output.

Control systems can be controlled manually or automatically.

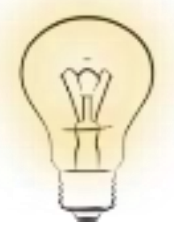

When talking specifically about artificial lighting, a lighting control system can be described as a group of components that allows you to control the output of an artificial lighting system. This could be both activating (turning on), deactivating (turning off) as well as adapting the current state of the artificial lighting (adapting the luminous flux or changing the light colour or the colour temperature (correlated colour temperature: CCT)).

The same approach can be applied to control of shading. In this case, the output device are motors which can move shades up and down or put them in a specific position. Motors can also operate slats or louvers and adjust their tilt angles to block sunlight penetrations. When reflective slats are used, daylight and sunlight penetration can be controlled and distributed inside following a specific pattern.

\subsection{Major components of control systems: input, control, output}

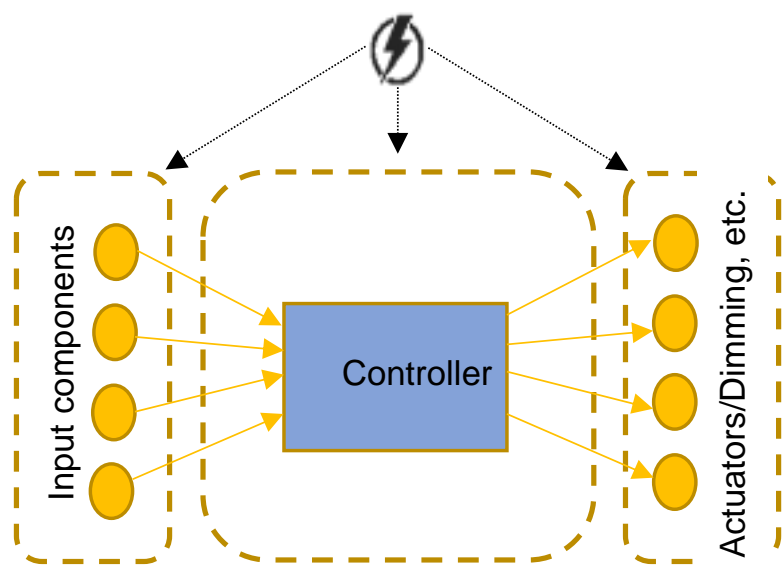

INPUT CONTROL - PROCESS OUTPUT

\section{PROGRAMMING}

(Possibly with Artificial

Intelligence - A.I.)

Figure 1. Control systems generally consist of 3 major components: input, control process and output.

In an automatic lighting control systems, one or more sensors perform a certain 'observation' (e.g. detection of movement, measurement of amount of entering light, ...) and convert the measurements into a signal that can be passed on to the controller. The sensors are often the most 'visible' (and thus characteristic) component of automatic lighting control systems. In case of manual control systems, no sensors are integrated in the system. The input is carried out by the user itself, e.g. by switch or a push button.

Once the controller has received the signal, it processes the signal (possibly taking into account certain programmed - parameters) to a 'description of action' and sends this to the actuator of the shading system or the 
driver of the lamp output). In case of lighting, this 'description of action' could be e.g. dimming or turning on or off the artificial lighting.

In case of a sun shading system, it could be e.g. move the shade to a specific position (actuator).

Finally, the actuator performs the action. In artificial lighting, the most well-known actuators are the ballast (fluorescent lighting) or the driver (led lighting) of the lighting luminaire.

In both manual as automatic control systems, the 3 major components of a system can appear both as individual components as well as integrated in a single device.

Several components have to be able to exchange information. In order to realize that, they need to be able to 'speak the same language'. The communication between the components can be done both analogue and digitally.

\subsection{Open loop vs. closed loop controls}

There are two common classes of control systems, open loop control systems and closed loop control systems.

In an open loop control system, the output generated by the system does not impact the input from the subsequent observation performed by the input components nor the action defined by the controller of the system. No feedback of the system is used in the control process. Thus, the control process is an open loop.

A closed-loop control system on the other hand takes the current output into account and alters it to the desired condition. The control system uses its current output in the subsequent control step. By using this feedback, the control process has become a closed loop. It allows results of the system to converge towards a desired value through a multiple step process.

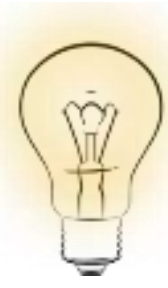

A very typical example of lighting control systems that exist both as an open loop and as a closed loop system, is a daylight control system, which automatically adjust the artificial light levels depending on the daylight penetration. Systems that use sensors only measuring daylight (because they are placed outside or they are pointed towards the windows) are open loop systems. Systems which are positioned in such a way that they measure both daylight and artificial lighting are closed loop systems.
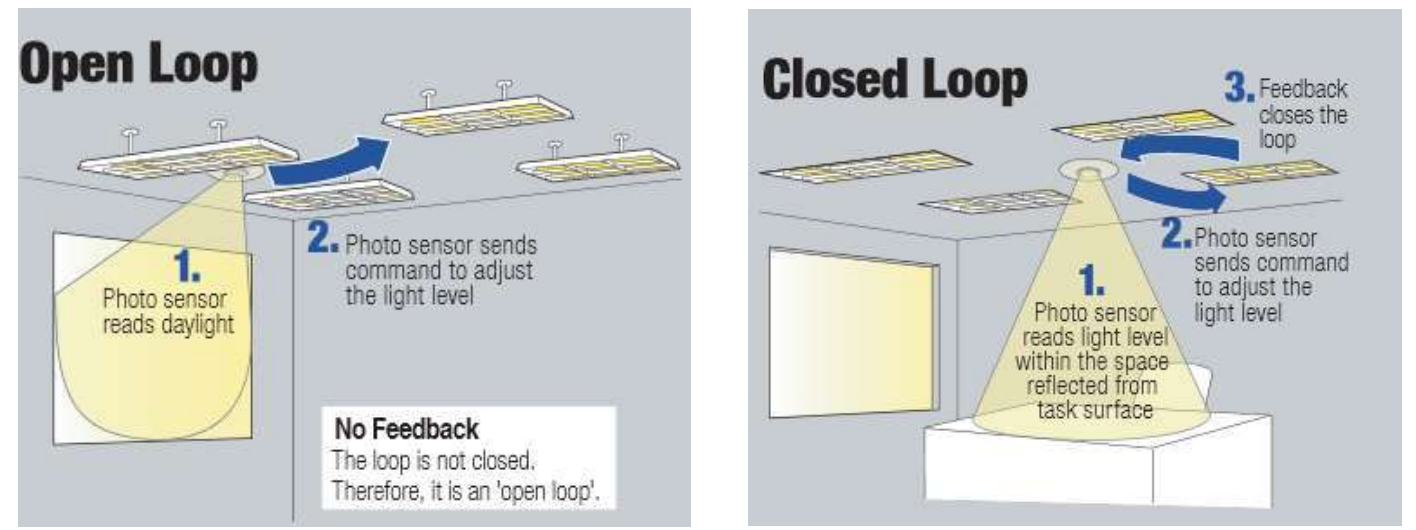

Figure 2. For lighting controls, sensors can read outside luminous quantities (open loop) or inside quantities (closed loop).

In a closed loop electric lighting system luminaires are often equipped with their own sensor, typically an illuminance sensor facing downward (with a sensitivity limited to a specific angle). This is typically useful to maintain a given level of illuminance when daylight can penetrate the space. It can be coupled with a presence sensor, to provide electric light only when needed, and with the minimum amount.

Sometimes the sensor can be externalized (outside the luminaire). 


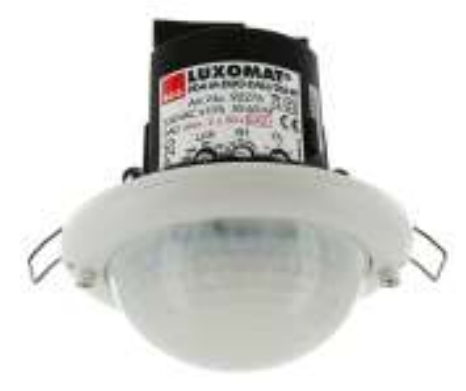

Figure 3. Example of a sensor used in a closed loop system, with the sensor located in the ceiling, but outside the luminaire (source LUXOMAT).

Closed loop is an approach to keep the illumination on a work plane, which means that light reflected back to the sensor in the ceiling is expected to remain constant too. Luminaires are equipped with their own sensor, typically an illuminance sensor facing downward (with sensitivity limited to a specific angle), allowing the adjustment of the electric lighting level up or down to keep the desired light level on the surface, and it is affected by both the daylight and the electric light.

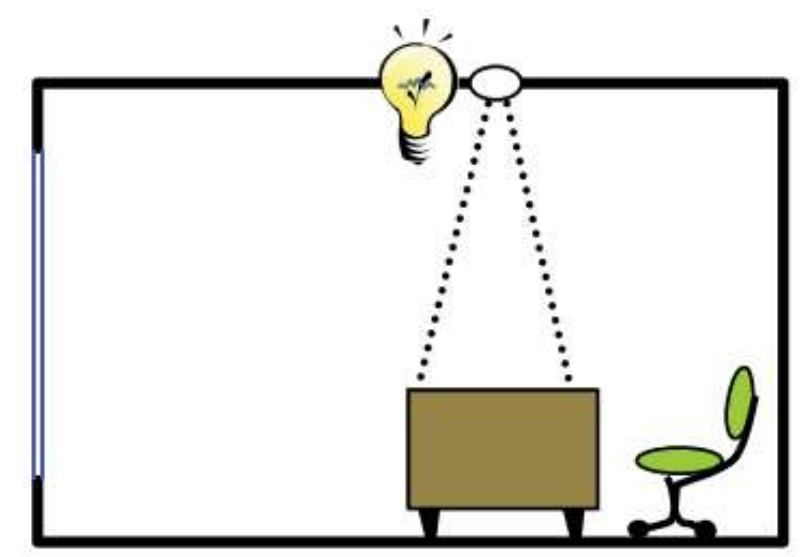

Figure 4. Close Loop-localized, with ceiling sensor (Source: Lutron).

Some observations concerning closed loop systems:

We can develop a closed loop system, with the sensors being shared by a group of luminaries.

Direct light coming from the fixtures and contributing to the light on the daylight sensor is referred as fixture feedback. To minimize the fixture feedback, daylight sensors must be positioned in a very smart way not to receive light from the fixtures and operate properly.

There are some possible alternative locations with indirect fixtures. For example; if the fixture is parallel to the window, the daylight sensor could be placed on the bottom of the fixture towards the window. If the fixture is perpendicular to the window, the sensor could again be placed under the pendant at the right distance from the window.

Trying to place the sensor in between fixtures in a row could help to avoid fixture feedback with recessed fixtures especially when the fixture has a wide surface area. 


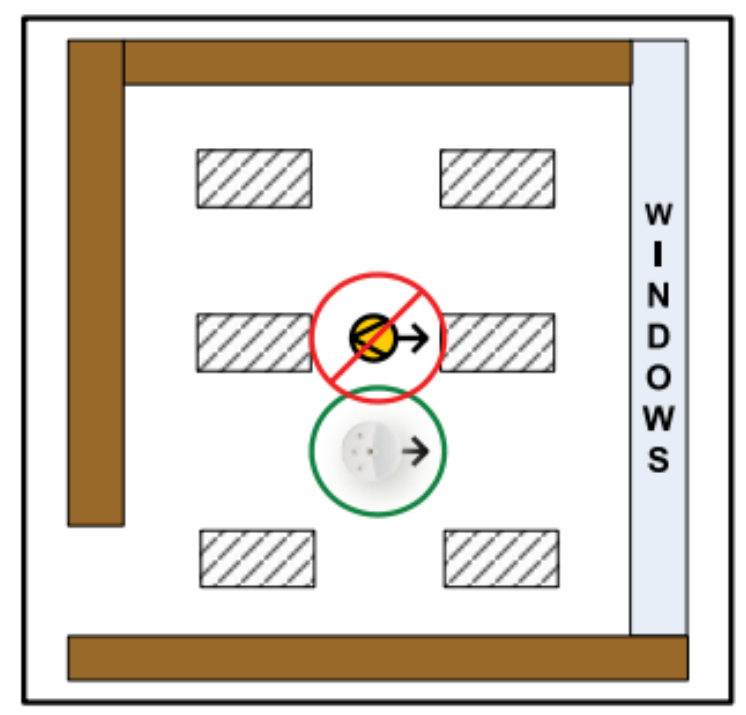

Figure 5. Fixture Feedback (Source: Lutron).

Open Loop: in this approach, the sensor measures only daylight, and sends the information to a control unit which then decides (with an appropriate programme) the action to conduct.

It is often a daylight sensor placed outside the building (on the façade or on the roof). There it does not see the electric lighting sources and provides and independent reading.

But it can also be a daylight sensor inside the room, pointed towards the window as well.

If it is inside and it is looking outside, the sensor can be calibrated to read a quantity in line with the usable light of the work surface, or the risk of glare for the occupants.

If it is outside, the calibration will require to take into account the optical role of the window component or the shading?

In both cases a precise on-site commissioning is essential.

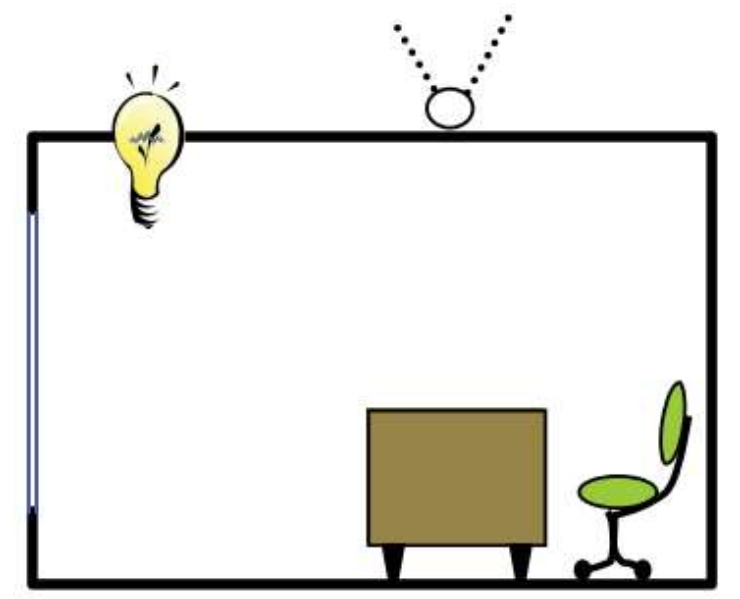

Figure 6. Schematic principle of an Open Loop control solution (Source: Lutron).

\subsection{Networks \& network topologies}

Networks are groups of devices or systems that function cooperatively or interdependently to transmit and receive information.

Different network topologies are possible, wired or wireless. The topology describes the physical or logical interconnections of the components in the network, needed for communication. The topology impacts the 
reliability and resilience of the network, the propagation time, the number of devices that can be connected and the distance the network can cover.

Below, the most well-known network topologies are shown.

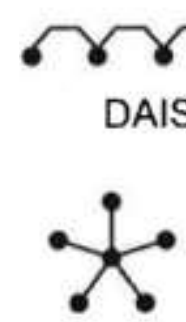

STAR
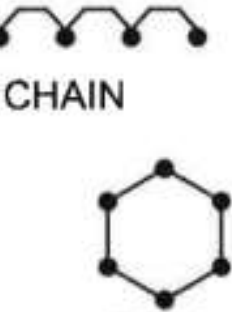

RING
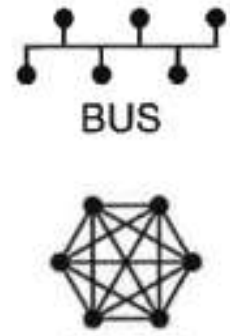

MESH

Figure 7. Various network topologies. Source: ANSI/IES: TM-23-17.

New generations wireless lighting control systems tend to use the mesh topology regularly. Wireless standards like Bluetooth, ZigBee and Thread all can work in the mesh topology.

In mesh networks, all nodes can connect to each other via multiple hops (jumps). Communication in a mesh network is possible by flooding, where every node in range receives messages and those which are acting as relays, retransmit the message to all other nodes in range. Bluetooth mesh networking uses this approach. Another way of communication is routing, where the network allows for continuous connections and reconfiguration around paths which are blocked or broken by "hopping" from node to node until the destination is reached.

An important advantage of mesh networks is that they are self-healing: the network can still operate when one node breaks down or a connection goes bad. So mesh networks tend to be very reliable, as there is more than one path between the source node and the destination node in the network.

Although the range from node to node of wireless standards like Bluetooth and ZigBee generally is rather limited (10-20 m), the total range of a network of nodes can be several times the distance between nodes, because of the meshing (the signal is regenerated at each node). However, it isn't endless as the time delay (latency) increases with the number of nodes in the path from source to destination and thus the system could become too 'slow'.

\subsection{Lighting Control in Building Management System}

A building management system (BMS), otherwise known as a building automation system (BAS), is a computerbased control system installed in buildings that controls and monitors the building's mechanical and electrical equipment such as ventilation lighting, power systems, fire systems, and security systems. A BMS consists of software and hardware; the software program, usually configured in a hierarchical manner, can be proprietary, using such protocols as C-Bus, Profibus, and so on. Vendors are also producing a BMS that integrates the use of Internet protocols and open standards;

A number of protocols (buses) are proposed and used in the building equipment industry:

- $\quad \mathrm{KNX}$ (Siemens)

- $\quad$ EtherCAT (Berkhof)

- $\quad$ LON (U.S.A., Schneider)

- $\quad$ CASAMBI (Low Power Bluetooth)

- VLAN

- DeviceNet

- XML

- SOAP

- BACnet

- Modbus,

- etc. 
One can consider lighting controls as a functionality of BMS systems: the lighting control strategy then uses the global BMS architecture to operate. Sensors send information to the BMS, and the software integrates actions concerning lighting. Then drivers in lighting equipment modify power according to orders received from the control unit.

Pros: appropriate when BMS is planned or installed: marginal costs

Cons: Commissioning and maintenance requires trained operators.

\subsection{Centralized vs. Decentralized systems}

There are a number of options concerning the architecture of the control systems, which can use local control of centralized controls.

\subsubsection{Decentralized control system (without PC Unit)}

Decentralized system means that device and sensor communicate without the need of a central unit. They are independent from it. This allows to operate locally independently from the rest of the building.

This can be found for electric lighting and daylighting.

Shading systems can be equipped with motors with a chip allowing to process information from a sensor. Information from the sensor can be sent to a large number of "active" components. [Ref WAGO]

- For each component (luminaries, shading), wireless actuator are necessary.

- They are installed between the components and their power supply.

- Wireless switches are paired individually with the actuators.

- Decentralized control system is ideal for small-scale installations and renovations (Source: EnOcean Alliance).

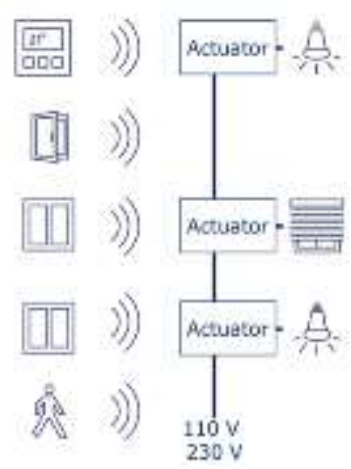

Figure 8. Decentralized Control System (Source: EnOcean Alliance).

\subsubsection{Centralized Control System}

- One central control unit is installed the whole building, or for each storey or section of a large place.

- It is possible to operate as a stand-alone system.

- It can be connected to the central building automation system. (Source: EnOcean Alliance) 


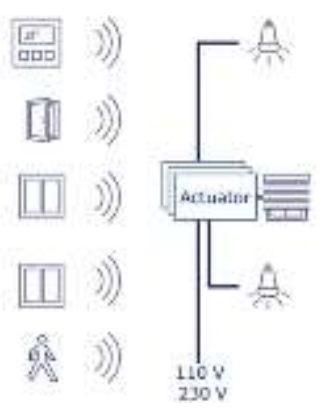

Figure 9. Centralized Control System (Source:EnOcean Alliance).

\section{Types of daylight control systems (shading)}

\subsection{Shading types}

The American activities in Attachment Energy Rating Council (AERC) is presenting a precise naming convention for daylighting devices: https://aercnet.org/resources/window-attachments/

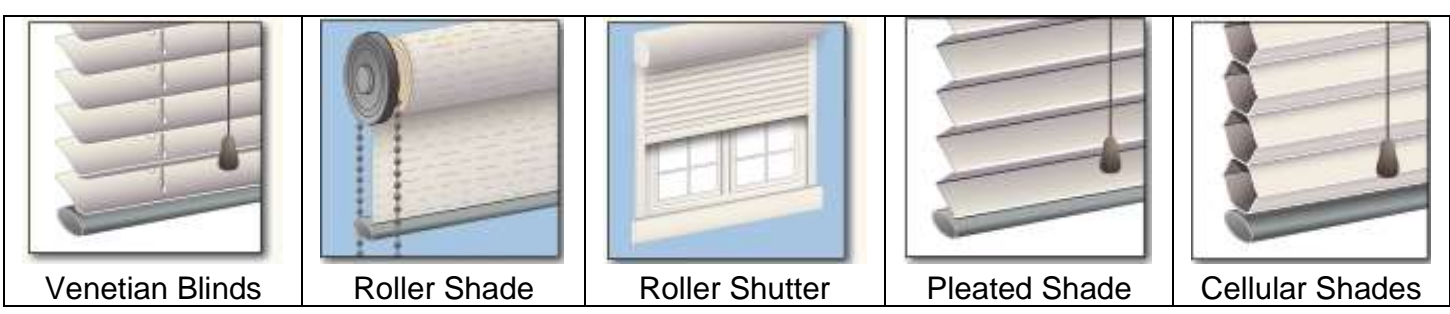

Figure 10. Examples of shading types.

Daylighting devices can be classified by different methods. The European Solar Shading Organisation ES-SO has suggested the following classification":

\begin{tabular}{|l|l|l|l|}
\hline Dynamic External & Static External & Dynamic Inbetween & Dynamic internal \\
\hline Venetian Blinds & Structural (e.g. fins) & Venetian Blinds & Venetian Blinds \\
Roller Shutters & Static membranes & Cellular shades & Pleated shade \\
Roller blinds & & & Cellular shade \\
& & & Roller blinds \\
\hline
\end{tabular}

And based on results of the KEEP COOL Project, ES-SO is presenting this overall quality criteria which are updated by the authors of this report.

\begin{tabular}{|c|c|c|c|c|c|c|c|c|c|c|}
\hline & \multicolumn{3}{|c|}{ External } & \multirow[t]{2}{*}{ Static } & \multicolumn{2}{|c|}{ Inbetween } & \multicolumn{4}{|c|}{ Dynamic Internal } \\
\hline $\begin{array}{ll}++ & \ldots \text { very good } \\
+ & \ldots \text { ok } \\
& \ldots \text { neutral } \\
- & \ldots \text { rather bad } \\
-- & \ldots \text { bad } \\
\text { n.r. } & \ldots \text { not relevant }\end{array}$ & 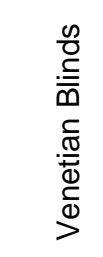 & 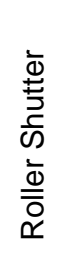 & $\begin{array}{l}\frac{\infty}{0} \\
. \overline{\overline{0}} \\
\bar{\emptyset} \\
\overline{\overline{0}} \\
\propto\end{array}$ & & 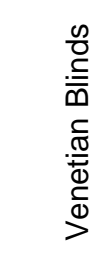 & $\begin{array}{l}\frac{\infty}{0} \\
\frac{\pi}{0} \\
\frac{\pi}{\omega} \\
\frac{\overline{0}}{5} \\
\frac{\bar{\sigma}}{\overline{0}} \\
0\end{array}$ & $\begin{array}{l}\frac{0}{0} \\
\frac{\pi}{\omega} \\
\frac{0}{0} \\
\frac{\pi}{\pi} \\
\frac{\omega}{0}\end{array}$ & 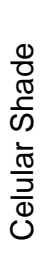 & 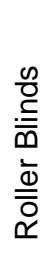 & 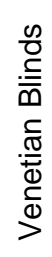 \\
\hline $\begin{array}{l}\text { Distributing/redirecting } \\
\text { Daylight }\end{array}$ & ++ & - & + & & & & & & & \\
\hline $\begin{array}{l}\text { variability of daylight } \\
\text { penetration }\end{array}$ & ++ & - & -- & -- & ++ & -- & -- & -- & ++ & -- \\
\hline $\begin{array}{l}\text { Controlling solar heat } \\
\text { gains }\end{array}$ & ++ & ++ & ++ & + & + & + & - & - & - & - \\
\hline variability of $g$-value & ++ & ++ & ++ & -- & ++ & ++ & ++ & ++ & ++ & ++ \\
\hline
\end{tabular}




\begin{tabular}{|l|c|c|c|c|c|c|c|c|c|c|}
\hline & & & & & & & & & & \\
\hline Controlling glare & ++ & ++ & ++ & 0 & ++ & ++ & ++ & ++ & ++ & ++ \\
\hline $\begin{array}{l}\text { Providing Privacy } \\
\text { (also at night times) }\end{array}$ & + & ++ & + & 0 & + & ++ & ++ & ++ & + & + \\
\hline $\begin{array}{l}\text { Providing contact to } \\
\text { the exterior }\end{array}$ & ++ & -- & ++ & & ++ & -- & - & -- & ++ & ++ \\
\hline $\begin{array}{l}\text { Increasing thermal } \\
\text { insulation (i.e. at night } \\
\text { in winter) }\end{array}$ & + & ++ & + & -- & 0 & 0 & + & + & + & + \\
\hline Wind Resistance & + & ++ & + & ++ & n.r. & n.r. & n.r. & n.r. & n.r. & n.r. \\
\hline
\end{tabular}

\subsection{Control strategies}

The ratio of motorized daylighting devices is steadily rising. Particularly the external devices are mostly motorized and ready for intelligent automation. In residential application, there is mostly no automation. It is up to the user to bring the devices in position. This is high risk for overheating especially in hot summers where users forget to do the right command (by lack of knowledge, or due to absence). New standards (starting in Austria), propose to integrate the benefits for energy saving associated to automated shading controls.

The most common control strategy is the rudimentary clock function, which just open the shading devices on specific times the day or solar positions of the day (e.g. in residential application, it opens when the sun rises and closes two hours later than). This clock function can be logically connected to an illumination level, i.e. if it is darker than $201 x$, assume to be night-time and close the devices.

In non-residential buildings the standard control is based on the detection of global horizontal or global vertical irradiation (i.e. measured on roofs and mathematically transformed to vertical values per façade orientation). If a specific threshold is achieved the daylighting devices move into the defined position. For venetian blinds, this includes both position and tilt angles position: $0^{\circ}$ is horizontal, $90^{\circ}$ is fully closed. Venetian blinds are generally moved fully closed $\left(90^{\circ}\right.$ position) or to a cut-off angle, which is the minimum tilt angle that blocks direct solar penetration. Or in other words, blocks the sight of sun from each possible eye position of occupants. This cut-off tilt angle allows the daylight penetration while reducing solar heat gains significantly. This cut-off tilting strategy is commonly called "sun tracking" or "solar tracking". For all other devices the standard movement command is only a position, generally completely down. Main purpose of this strategy is to reduce solar heat gains and/or control glare. A differentiation between solar and visual impacts is not established.

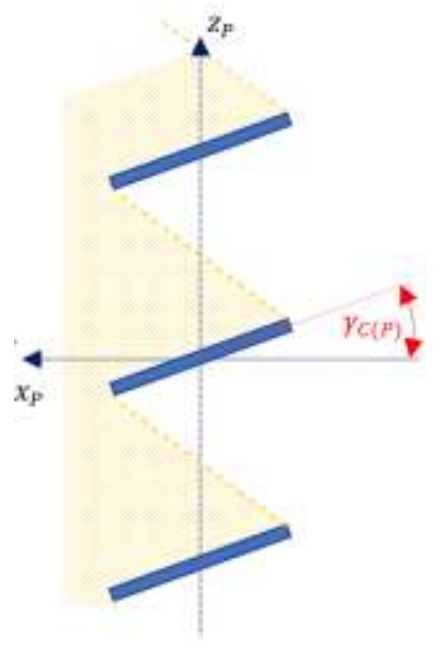

Figure 11. Cut-Off Tilt angle.

"Shadow Tracking" is another approach for providing contact to the dynamics of the external world. It defines the depth of solar penetration into rooms. By this, the users are enabled to define a desired connection to the solar beam, e.g. they can allow sun penetration to $50 \mathrm{~cm}$ on a windowsills or floors, where this high luminance and solar gain does not cause any problems regarding glare and overheating. 
All control strategies are overruled by device-safety features: First, if wind above a specific threshold is detected all devices are retracted into safe position (i.e. fully retracted). The position of wind detector might be on the roof or on the façade. Second, if there is precipitation at low temperatures, the devices do not move for breakage reduction of mechanics.

All strategies mentioned above do not consider overall energy and comfort effects of the daylighting device: there is no connection between the energy demands of artificial lighting or heating/cooling and the daylight/solar energy supply. Device characteristics, as transmittance, openness factors or any other angular depending data are mostly not fed in control strategies: sensor provide information, and commissioning is needed to take into account these attributes.

\subsection{Motorized or not motorized}

\subsubsection{Residential building}

Below, we identify a number of trends and classical issues related to the market of shading for windows, for several residential buildings

Table 1. Analysis of the market of shading systems (trends are mostly in Europe since there was no contribution on this topic for other countries).

\begin{tabular}{|c|c|}
\hline \multicolumn{2}{|c|}{ Residential buildings } \\
\hline External Shading & Internal shading \\
\hline $\begin{array}{l}\text { It is common in southern Europe, and countries with } \\
\text { warm climate. It is not the case in northern Europe }\end{array}$ & $\begin{array}{l}\text { Manual curtains for intimacy, thermal comfort, } \\
\text { darkness in summer (sleeping quality) and even } \\
\text { acoustical comfort }\end{array}$ \\
\hline $\begin{array}{l}\text { It is used as solar protection, and also to keep heat } \\
\text { inside during winter (with insulating product) }\end{array}$ & $\begin{array}{l}\text { Products are bought by consumers in distribution } \\
\text { stores at rather low prices }\end{array}$ \\
\hline Effects of anti-theft are promoted & Products are often installed by professionals. \\
\hline & $\begin{array}{l}\text { Problem of increase of vapour condensation on glass } \\
\text { due to internal shading }\end{array}$ \\
\hline \multicolumn{2}{|c|}{ Motorized controls } \\
\hline $\begin{array}{l}\text { Motorization is more and more common, with manual } \\
\text { switches on the internal wall }\end{array}$ & Motorization of internal shading is rare \\
\hline \multicolumn{2}{|l|}{$\begin{array}{l}\text { When control is automatic, often sensor is a wind } \\
\text { sensor. Note issue of closing shading too often when } \\
\text { a wind sensor is related to many apertures on the } \\
\text { same façade. }\end{array}$} \\
\hline \multicolumn{2}{|l|}{$\begin{array}{l}\text { Problem to close or open shade in case of electrical } \\
\text { failure }\end{array}$} \\
\hline Market of home automation is growing fast & \\
\hline
\end{tabular}




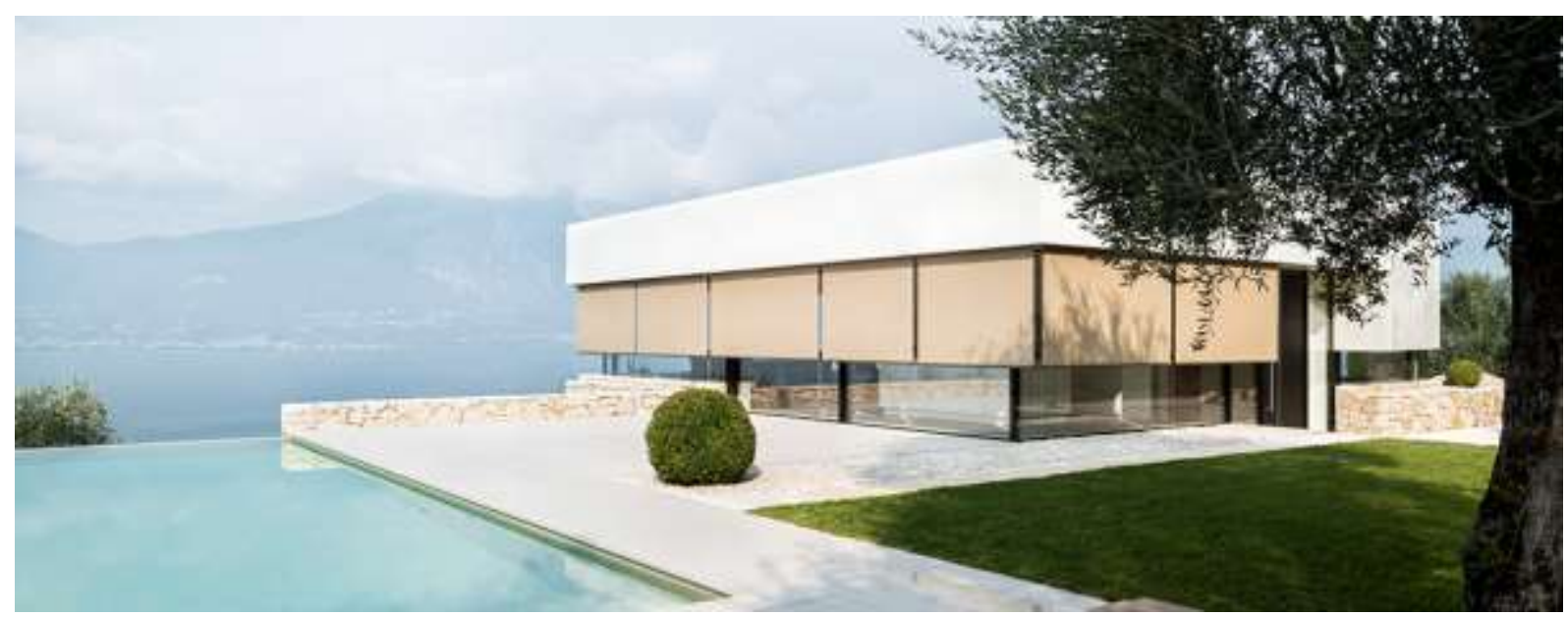

Figure 12. External Textile Shading (Source: https://www.hella.info).

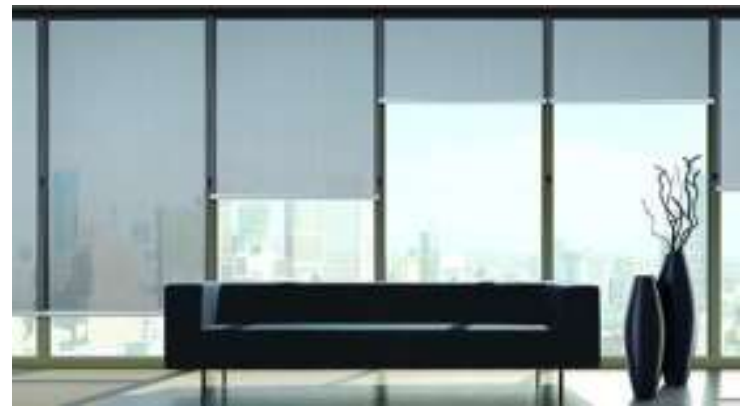

Figure 13. Internal Textile Shading (Source: http://turnerarc.com.au/internal-systems).

\subsubsection{Non-residential buildings}

The same analysis was conducted for the non-residential building sector. A new configuration is added: shading imbedded in window components.

Table 2. Analysis of various shading solutions in non-residential buildings.

\begin{tabular}{|c|c|c|}
\hline \multicolumn{3}{|c|}{ Non-residential buildings } \\
\hline External & Imbedded in window component & Internal \\
\hline $\begin{array}{l}\text { Movable textile shades, } \\
\text { aluminium slats, or fixed } \\
\text { elements (metal, glass) }\end{array}$ & $\begin{array}{l}\text { Non-motorized solutions are raer. } \\
\text { rare } \\
\text { See WICONA-Aluminium } \\
\text { FINSTRAL - PVC }\end{array}$ & $\begin{array}{l}\text { Products are internal blinds or } \\
\text { textile shades }\end{array}$ \\
\hline $\begin{array}{l}\text { Need of external irradiance } \\
\text { sensor to operate in an } \\
\text { optimal way }\end{array}$ & No need for wind sensor & $\begin{array}{l}\text { No need for wind sensor } \\
\text { No use of external irradiance } \\
\text { sensor in general }\end{array}$ \\
\hline \multicolumn{3}{|c|}{ Motorized controls } \\
\hline $\begin{array}{l}\text { Motorization is standard, for } \\
\text { textile and louvers }\end{array}$ & $\begin{array}{l}\text { Motorized solutions are standard } \\
\text { Check WICONA-Aluminium } \\
\text { FINSTRAL - PVC }\end{array}$ & \\
\hline $\begin{array}{l}\text { Most common sensor is } \\
\text { wind sensor }\end{array}$ & No need for wind sensor & No need for wind sensor \\
\hline $\begin{array}{l}\text { Only } 25 \% \text { of motorized } \\
\text { external shading are using }\end{array}$ & $\begin{array}{l}\text { Only a small fraction of motorized } \\
\text { shading is using an external } \\
\text { irradiance sensor }\end{array}$ & \\
\hline
\end{tabular}




\begin{tabular}{|l|l|l|}
\hline $\begin{array}{l}\text { an external irradiance } \\
\text { sensor }\end{array}$ & \\
\hline $\begin{array}{l}\text { Less than } 5 \% \text { allow } \\
\text { adjustment of tilt angle of } \\
\text { slats as a function of solar } \\
\text { position }\end{array}$ & $\begin{array}{l}\text { Very few systems allow adjustment } \\
\text { of tilt angle of slats as a function of } \\
\text { solar position }\end{array}$ & \\
\hline
\end{tabular}

In non-residential buildings, most shading systems are motorized, and controls are mostly based on wind or irradiance measurement from the façade. Automatic and motorized adjustment of tilt of slats is still rather rare.

\section{Types of electric lighting control systems}

\subsection{Electric lighting and control systems: an introduction}

Ever since the invention of the incandescent lamp in the 1800's, there has been a striving for higher luminous fluxes while consuming less energy. Existing technologies were optimized and new technologies were developed.

In the last 40 years (after 1980), the lighting industry focused on reducing energy consumption, meaning increasing luminous efficacy of sources and improving luminaire design and optics. This led to a drastic reduction of electric lighting power density (now in the range of $4-8 \mathrm{~W} / \mathrm{m}^{2}$ for most applications except in retail stores). With an efficiency of 150 to $200 \mathrm{~lm} / \mathrm{W}$ and more, the LED is by far the most energy efficient light source nowadays. The evolution of lighting sources toward LEDs is often called 'Ledification'.

Lighting control allow to reduce further the consumption of electricity for lighting. But most important, to adjust lighting to needs of occupants.

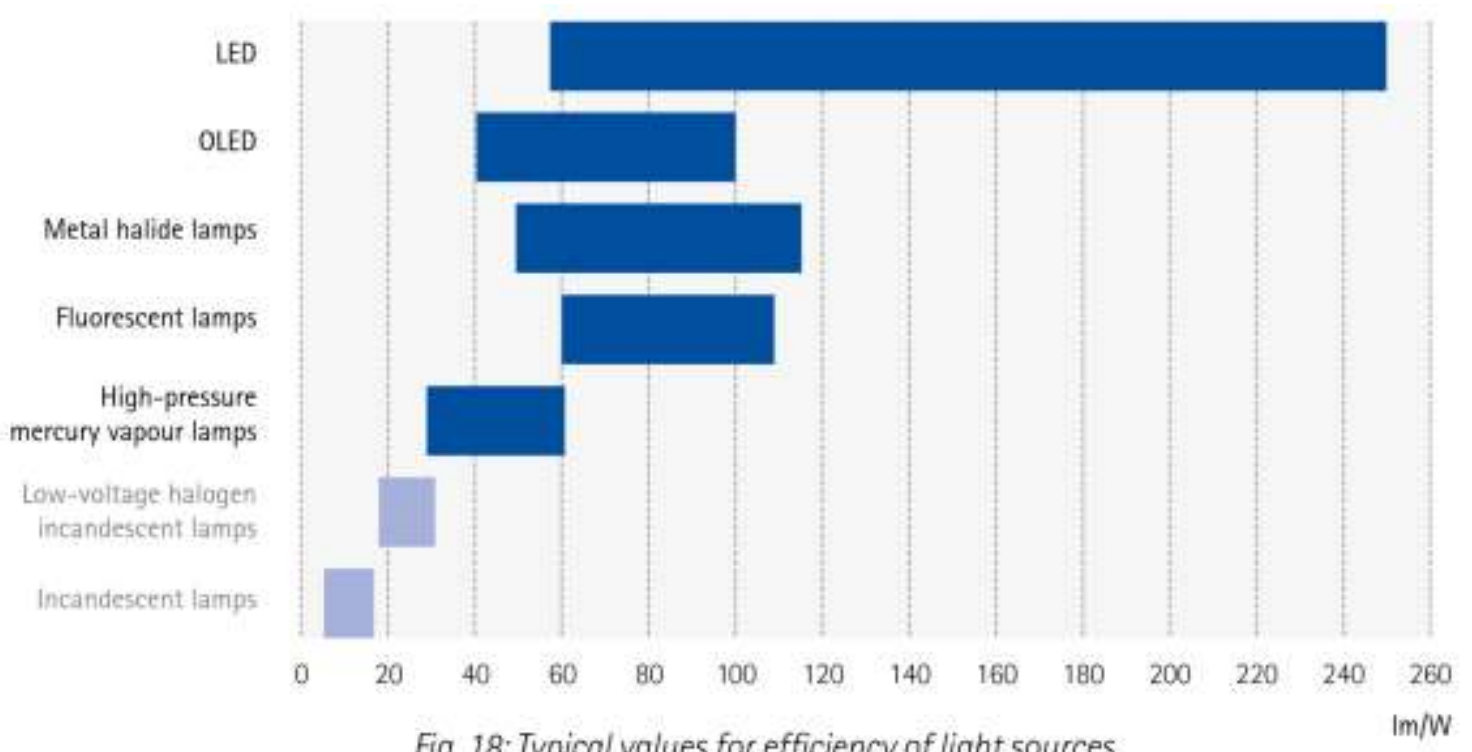

Figure 14. Luminous efficacy of different types of light sources anno 2019. With the LED revolution, luminous efficacy of white light sources can exceed $200 \mathrm{Im} / \mathrm{W}$. Source: https://www.etaplighting.com/en/downloads/general : Dossier:

LED.

This has led to an enormous boom of the led market since 2010. The energy efficiency combined with the quality of light and the flexibility that led offers has led to the fact that led is used in the majority of tertiary lighting projects currently. Tertiary meaning offices and commercial buildings 


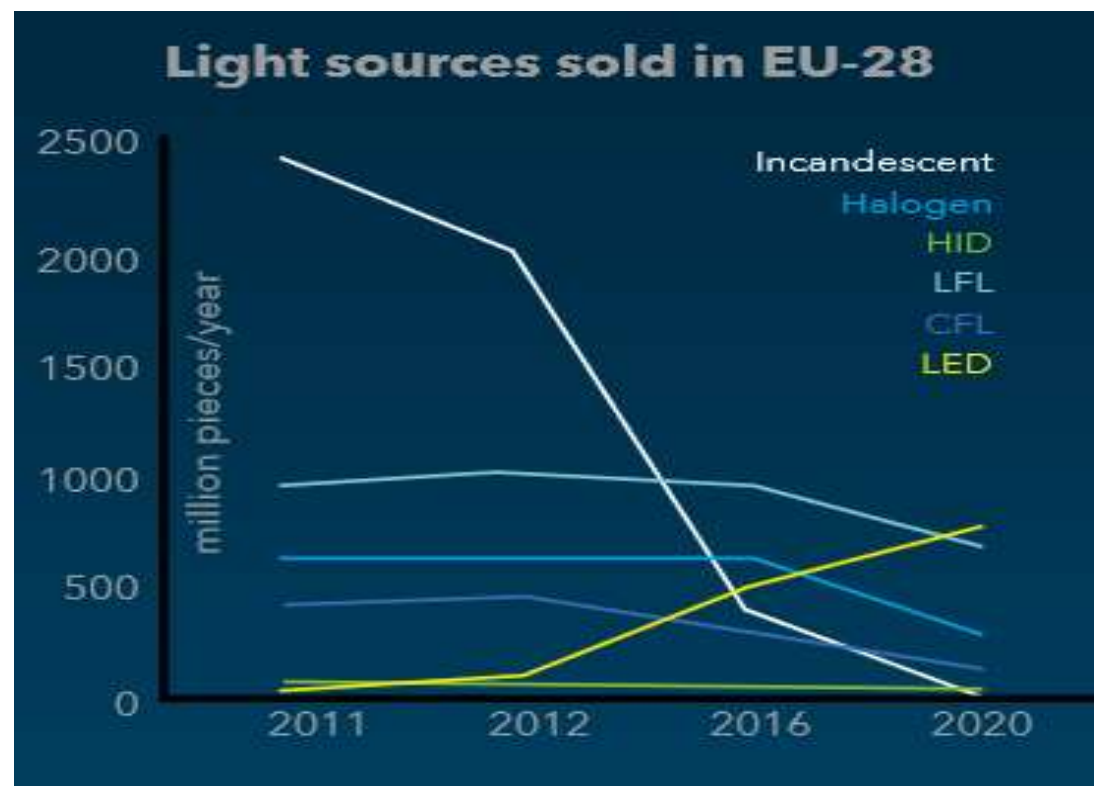

Figure 15. Combination of progress in luminous efficacy and reduction of costs leads to a progressive replacement of all light sources by LEDs Source: Lighting Europe - Strategic Roadmap 2025 of the European Lighting Industry.

Another important advantage of led lighting is that it can be controlled and adjusted very easily. A logical effect of the breakthrough of LEDs has been the digitalization of lighting and the integration of more (intelligent) lighting control systems.

The level of intelligence of the systems depends on different things, e.g. the level of connectivity, the feedback of the systems, etc. The aim is to make systems perform in real life conditions in the most effective way (for both energy consumption, as well as comfort, safety, ...).

The graph above (Figure 15) focusses on the available technologies for lighting control, rather than giving insight in connectivity and/or monitoring related aspects. The technologies for electric lighting control are classified based on the type of observation/detection (input component of the control system) the systems use. The highest level of classification is the distinction between manually controlled systems and automatically controlled systems.

Which control system, or which combination of control systems, should be integrated in a specific situation, depends on the specific conditions where it should be integrated (type of building / room; usage of the building, etc.) and the user requirements (visual comfort, energy savings, etc.).

It's important to understand that the (visual) comfort and safety of the user should always be considered as the most important requirement, even if saving energy is often the motivation for taking the decision to integrate lighting control systems.

This is not only a matter of well-being, comfort or health. Research has proven that the initial construction cost (incl. lighting infrastructure) and operations / maintenance costs of building come to less than $10 \%$ of the total cost of a building over its lifetime. Costs related to people are much more substantial. Comfortable and healthy buildings is expected to reduce the costs of staff at the one hand, and

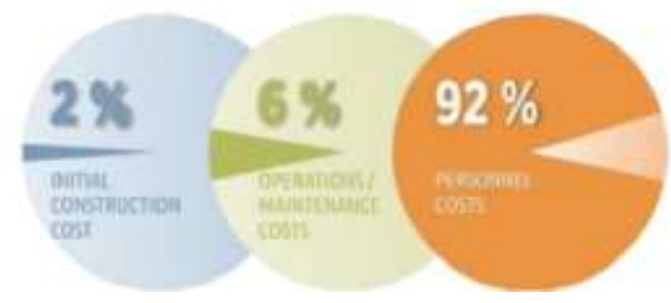
at the other hand make them more productive, have lower costs of sickness,...

Although the initial cost of the building and its technical installations are often seen as the most critical, it's important to also look at the future costs related to the initial decisions you've made.

This approach requires that a new cost-benefit model has to be developed, linking lighting benefits to increased well-being, increased productivity, increased functionality of spaces, and increased value of spaces (rental value or market value). 


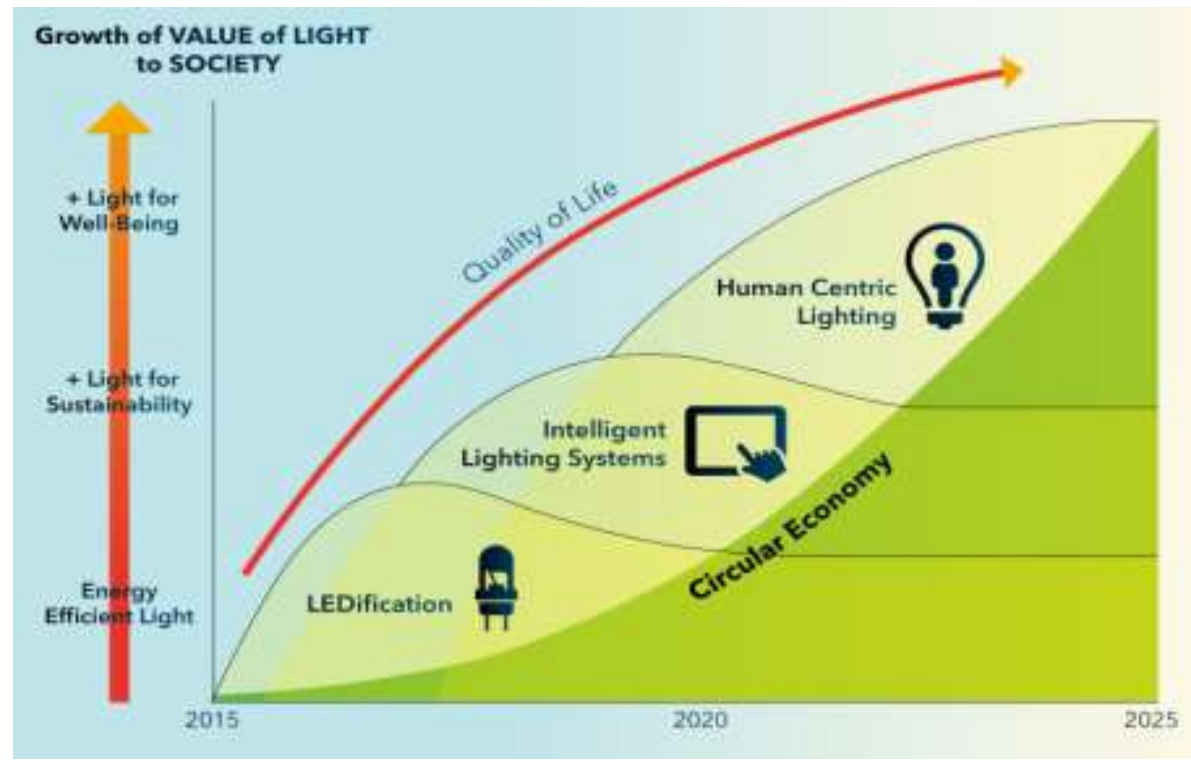

Figure 16. With reduction of Total Cost of Ownership (TCO) of light sources, focus of the industry is concentrating now on added benefits of light to justify the investment costs. Source: Lighting Europe - Strategic Roadmap 2025 of the European Lighting Industry.

However, in this document, there is a focus on the energy related aspects.

Before going into the details of different types of lighting control systems, some general principles that have an impact on energy use should be explained. They are listed below

Before looking for energy efficient solutions, efforts to reduce demand for energy should be investigated. For example in transportation, reducing need for automobile transport is a, item to tackle before investing in energy efficient automobiles.

\section{- $\quad$ Trias Energetica:}

The Trias Energetica concept is a 3-step strategy to make an energy efficient design. The 3 steps of the Trias Energetica are basic rules of thumb for the sustainable design of buildings. Firstly, the energy demand should be reduced. Looking at (artificial) lighting, this would mean that:

1. Daylight penetration in the building should be allowed in a well-considered way.

2. Additionally, the artificial lighting should make use of an energy efficient technology. Nowadays, LED lighting is the standard, as it is can provide very qualitative light in a very energy efficient way.

3. Finally, lighting control systems can contribute to limiting the use of the artificial lighting (in time, in active power (dimming), ...).

The second step and the third step of the Trias Energetica include the use of sustainable energy sources and eventually, use fossil energy as efficiently as possible.

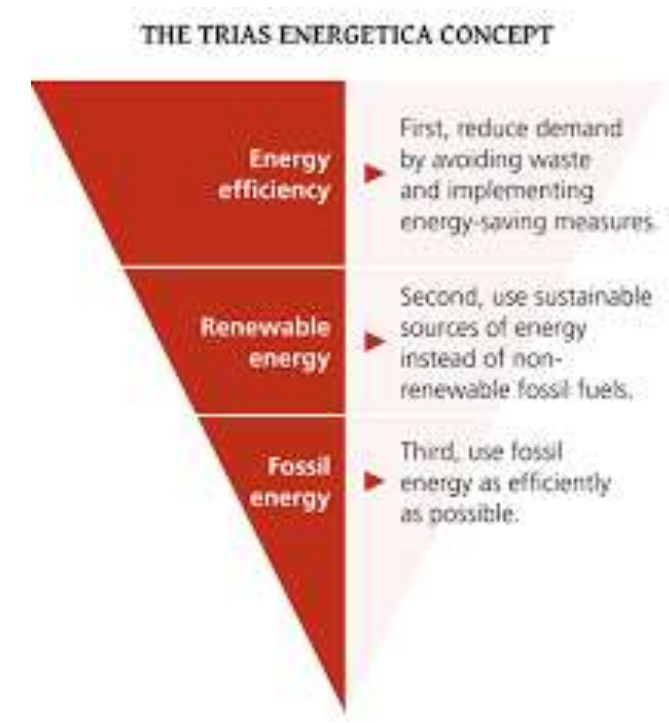

Source: www.ursa.com.

\section{- $\quad$ Rebound effect:}

With an efficiency of 150 to $200 \mathrm{~lm} / \mathrm{W}$ and more, the LED is by far the most energy efficient light source nowadays. People are aware of the fact that this technology is much more efficient than earlier technologies such as incandescent, halogen and even fluorescent lamps. However, this has an adverse effect on their behavior: people pay less attention to limiting the use of the artificial lighting as it is very energy efficient (and thus not very expensive). The fact that the energy savings from these new technologies are lower because of behavioral changes of the users is called the rebound effect. 


\section{- Energy savings: relative vs. absolute savings:}

When looking into estimated or realized energy savings, it is highly important to not only look at the relative energy savings (percentages), but also look into the absolute values (kWh;€). Situations exist in which the relative savings seem indicate that the system is definitely worth the investment (only looking from the energetic point of view), while the absolute savings are actually very limited.

E.g.: in a room with a very high amount of daylight penetration (average daylight factor of 5,3\%), a daylight control is integrated. Although we do not control daylight, we use the terminology Daylight control

Monitoring shows yearly savings up to $50 \%$ and more. The room is very often used. However, due to the high amount of daylight penetration, using the artificial lighting is often unnecessary and thus the 'light on' time is very limited (less than $\mathbf{5 0 0}$ hours/year). This is under the assumption that the users remember to turn off the light every day and always when there is enough daylight! This is highly questionable! Although the relative savings are $50 \%$ and more, the limited 'light on' time results in low absolute energy savings (kWh).

\section{- Installation, set up \& commissioning:}

It is of major concern to pay attention to the correct installation, initial set up and continuous commissioning of the lighting systems, including lighting control systems. Experience has shown that not taking the time for properly installing and setting up lighting control systems very often leads to inappropriate functioning or even malfunctioning of the control systems (as it is the case for a lot of technical installations / control systems). Proper installation and setup will result in high energy savings while still meeting all of the comfort requirements of the users.

Below, a review of various systems used in electric lighting control is presented. The analysis identifies:

- The major purpose of the technology

- How the technology works

- When it preferably should be used

- Aspects having an important impact on the performance of the system

This mapping demonstrates that during the selection process of a control system, both the context (type of building, usage, schedules, etc.) and the expectations on performances (expected energy savings, satisfaction of users, etc...) should be taken into account.

\subsection{Manual lighting control systems}

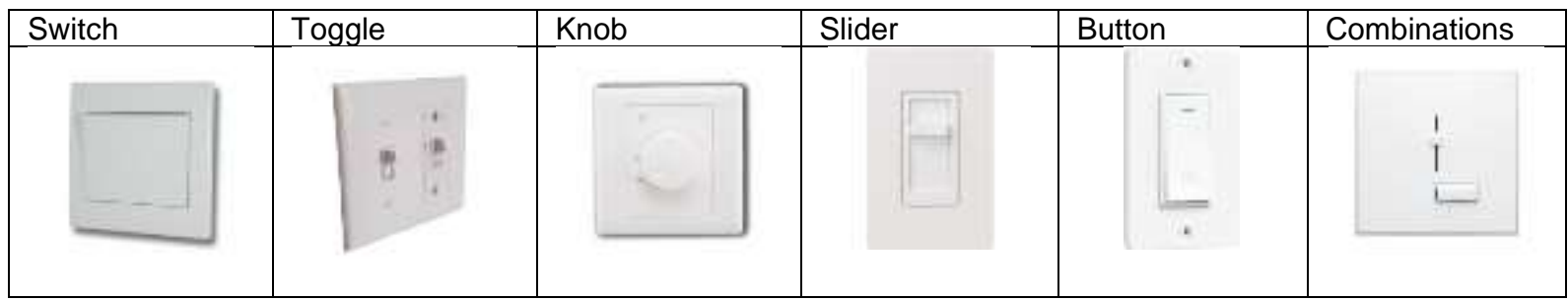

Figure 17. Examples of manual lighting control devices.

- Manually switching \& dimming

Major purpose: $\quad$ increasing the comfort and satisfaction level of the users by giving them personal control over the lighting installation. It enables them to create a specific atmosphere by setting scenes.

\begin{tabular}{|l|l|}
\hline $\begin{array}{l}\text { How does it } \\
\text { work? }\end{array}$ & $\begin{array}{l}\text { Most simple control using switches and/or dimmers to activate (turning on), } \\
\text { deactivate (turning off) as well as adapt the current state of the artificial lighting } \\
\text { (adapting the luminous flux). The interface of the switches and dimmers exists in } \\
\text { different forms: traditional wall components, touchscreens or remote controls, or } \\
\text { smartphones (/tablets/...), using an app. }\end{array}$ \\
\hline When to use it? & $\begin{array}{l}\text { Although automatic lighting control systems are likely to save more energy than } \\
\text { manual control systems (as user behaviour tend to be more ad hoc than }\end{array}$ \\
\hline
\end{tabular}




\begin{tabular}{|c|c|}
\hline & $\begin{array}{l}\text { systematic, and thus unpredictable), it is often advisable to integrate additional } \\
\text { manual lighting controls for overriding the system. Giving users somehow } \\
\text { personal control over the lighting installation has a positive effect on their } \\
\text { comfort, satisfaction and performance. }\end{array}$ \\
\hline $\begin{array}{l}\text { Aspects having a } \\
\text { major impact on } \\
\text { effective } \\
\text { performance of } \\
\text { the system }\end{array}$ & $\begin{array}{ll}\text { - } & \text { Size of the zones that are controlled individually } \\
\text { (complete space controlled by one manual input component } \\
\text { (switch/dimmer), or divided in separate zones?) } \\
\text { - } \quad \text { Behaviour of the occupants of the space } \\
\text { - This solution is robust, leading to minimized maintenance (if it does not } \\
\text { require a battery) }\end{array}$ \\
\hline Additional info & 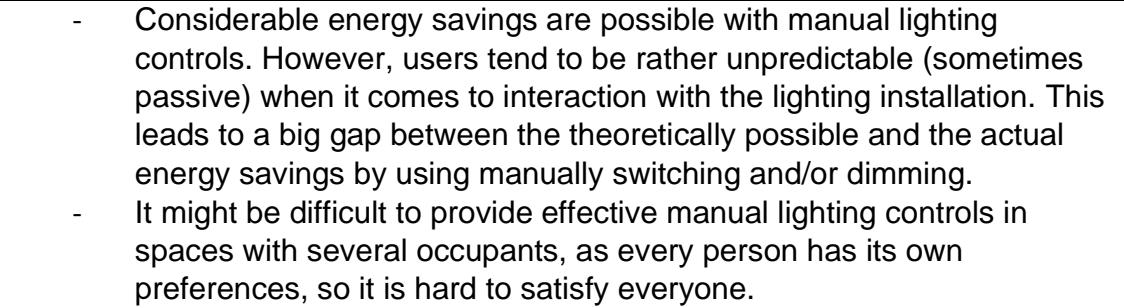 \\
\hline
\end{tabular}

- Adjusting colours / colour temperatures

Major purpose: $\quad$ increasing the comfort and satisfaction level of the users by giving them personal control over the lighting installation. It enables them to create a specific atmosphere by setting scenes.

\begin{tabular}{|l|l|}
\hline $\begin{array}{l}\text { How does it } \\
\text { work? }\end{array}$ & $\begin{array}{l}\text { Manual input components changing the light colour or the colour temperature. } \\
\text { The interface of the input components exists in different forms: traditional wall } \\
\text { components, touchscreens or remote controls, or smartphones (/tablets/...), } \\
\text { using an app. }\end{array}$ \\
\hline When to use it? & $\begin{array}{l}\text { Where application of this type of lighting control system is strongly } \\
\text { recommended for occupant well-being } \\
\text { Adjustment of colours is used for scene setting and for architectural lighting. } \\
\text { Adjustment of colour temperatures is used to create a specific atmosphere } \\
\text { and/or to influence the well-being and performance of the users. } \\
\text { This feature could, amongst others, make sense in hospitals, hotels, } \\
\text { restaurants. }\end{array}$ \\
\hline $\begin{array}{l}\text { Aspects having a } \\
\text { major impact on } \\
\text { effective } \\
\text { performance of } \\
\text { the system }\end{array}$ & \begin{tabular}{l} 
Speed of dimming / changes \\
\hline Additional info
\end{tabular} \\
$\begin{array}{l}\text { Using led lighting, it could be advisable to be able to lower the colour } \\
\text { temperature ('warmer' light) when lowering the power, in order to make it } \\
\text { more acceptable to the occupants. } \\
\text { (https://en.wikipedia.org/wiki/Kruithof curve) } \\
\text { The reference term is 'tunable white' (he ClE-definition now is Integrative } \\
\text { lighting) when the system allows to keep the light white, but vary the colour } \\
\text { temperature (warm vs. cold white light). Salesperson often use the term } \\
\text { Human Centric Lighting wrongly to describe tunable white. }\end{array}$ \\
\hline
\end{tabular}

\subsection{Automatic lighting control systems}

As said before, building occupants tend to be rather unpredictable when it comes to interaction with the lighting installation. People may have a limited capacity to anticipate consequences of their actions on the controls: when electric lighting is on, it is often difficult to predict what the space will look like if the electric lighting is (partly) turned off or dimmed, in case of daylight penetration. Besides, the users cannot be expected to adjust the light settings at all time, especially in non-residential environments. Finally, not taking the reasons above into account, users tend to be just passive sometimes when it comes to interaction with the lighting installation. 
Therefore, automatic lighting controls are an essential component of a strategy aiming to reduce electric lighting consumption while still providing the desired visual comfort to the users. For automatic lighting control systems, it is very important to install and set up the system correctly. If not, the system will not work properly once it is used.

- Time based control - light level

Major purpose: $\quad$ saving energy by limiting the time that the lighting is turned on to the time that occupancy in the space is expected or lighting in the space is desired (e.g. lighting without occupancy for safety reasons or commercial reasons (shop lighting)). The lighting can be switched on/off, switched to another light level or dimmed down.

\begin{tabular}{|c|c|}
\hline $\begin{array}{l}\text { How does it } \\
\text { work? }\end{array}$ & $\begin{array}{l}\text { Change of the status of the artificial lighting (on/off; dimming level), } \\
\text { based on a programmed time scheme (clock integrated in the system). } \\
\text { Using this system guarantees that the artificial lighting will not stay } \\
\text { turned on outside a given (programmed) time scheme. }\end{array}$ \\
\hline When to use it? & $\begin{array}{l}\text { Using this strategy is mainly effective in buildings (/ spaces) with a } \\
\text { rather predictable occupancy / usage pattern (e.g. retail, museums ...). }\end{array}$ \\
\hline $\begin{array}{l}\text { Aspects having } \\
\text { a major impact } \\
\text { on effective } \\
\text { performance of } \\
\text { the system }\end{array}$ & $\begin{array}{l}\text { - It is suggested to use this system only for automatically turning off the } \\
\text { lighting. Manually turning on the artificial lighting instead of } \\
\text { automatically turning it on avoids situations where lighting would } \\
\text { automatically be turned on, while there is no need for the lighting to be } \\
\text { turned on (e.g. nobody is present, because of deviation from the time } \\
\text { scheme). }\end{array}$ \\
\hline Additional info & $\begin{array}{l}\text { - It is important to avoid that the lighting is switched off all of a sudden, } \\
\text { because this could cause dangerous situations. Possible solutions are } \\
\text { switching off the lighting in different phases (dividing the lighting } \\
\text { installation in groups and switching of group by group) or first dimming } \\
\text { the lighting and afterwards switching it off. } \\
\text { - To give potential occupants the ability to switch on the lighting again, } \\
\text { the automatic control system should be equipped with a manual } \\
\text { override. } \\
\text { It is possible that it's desired that a building / space is lighted, while } \\
\text { there is no occupancy (e.g. for prevention of burglary (control use of } \\
\text { occupancy); commercial reasons (shop lighting)). } \\
\text { This type of automatic lighting control system is very robust and has a } \\
\text { rather low cost. } \\
\text { Depending on the type of system, several functions are available: e.g., } \\
\text { the time scheme can vary on a daily, weekly,... basis ; automatically } \\
\text { switching between Standard time' and 'Daylight Savings time' ... }\end{array}$ \\
\hline
\end{tabular}

\begin{tabular}{|l|l|}
\hline Variant 2 : time based control using relative points in time \\
\hline $\begin{array}{l}\text { How does it } \\
\text { work? }\end{array}$ & $\begin{array}{l}\text { Automatic change of the status of the artificial lighting a certain time } \\
\text { after another action took place. The 'purest' application is the staircase } \\
\text { time switch, which switches off the light automatically a certain time } \\
\text { after the occupant had turned it on manually. }\end{array}$ \\
\hline When to use it? & $\begin{array}{l}\text { Using this strategy is mainly effective in spaces that are used } \\
\text { periodically during short periods of time (e.g. hall, corridor, staircase ...). }\end{array}$ \\
\hline $\begin{array}{l}\text { Aspects having } \\
\text { a major impact } \\
\text { on effective } \\
\text { performance of } \\
\text { the system }\end{array}$ & $\begin{array}{l}\text { - This type of automatic lighting control system is very robust and has a } \\
\text { rather low cost. } \\
\text { Additional info } \\
\text { Depending on the type of system, several functions are available: e.g. }\end{array}$ \\
\hline
\end{tabular}




\begin{tabular}{|l|ll|}
\hline- & $\begin{array}{l}\text { To give potential occupants the ability to switch on the lighting for a } \\
\text { longer period (e.g. cleaning services), it is desired that the automatic } \\
\text { control system is equipped with a manual override. }\end{array}$ \\
\hline
\end{tabular}

- Time based control - colours / colour temperatures

Major purpose: $\quad$ Creating a specific atmosphere and/or influencing the well-being and performance of the users of the space

\begin{tabular}{|l|l|}
\hline Variant 1: time based control using absolute points in time \\
\hline $\begin{array}{l}\text { How does it } \\
\text { work? }\end{array}$ & $\begin{array}{l}\text { Change of the colours / colour temperatures of the light emitted by the artificial } \\
\text { lighting, based on a programmed time scheme }\end{array}$ \\
\hline When to use it? & $\begin{array}{l}\text { Only after a clear investigation of the effects which are looked for. } \\
\text { Adjustment of colours is used for scene setting and for architectural lighting. } \\
\text { Adjustment of colour temperatures is used to create a specific atmosphere } \\
\text { and/or to influence the well-being and performance of the users. } \\
\text { This feature could, amongst others, make sense in hospitals, retail, restaurants. }\end{array}$ \\
\hline $\begin{array}{l}\text { Aspects having a } \\
\text { major impact on } \\
\text { effective } \\
\text { performance of } \\
\text { the system }\end{array}$ & $/$ \\
\hline Additional info & $/$ \\
\hline
\end{tabular}

- Occupancy detection

Major purpose:

saving energy by limiting the time that the lighting is turned on to the time that the space is actually occupied. The lighting can be switched on/off, switched to a lower lighting level or dimmed down.

\begin{tabular}{|c|c|}
\hline \multicolumn{2}{|c|}{ Variant 1 : presence detection } \\
\hline $\begin{array}{l}\text { How does it } \\
\text { work? }\end{array}$ & $\begin{array}{l}\text { As soon as the detector detects there is human activity in the space, the } \\
\text { artificial lighting controlled by the detector is automatically turned on. As } \\
\text { long as human activity is detected, the artificial lighting stays turned on. } \\
\text { When the detector doesn't detect any human activity during a } \\
\text { predefined period (the switch-off delay time), the artificial lighting is } \\
\text { dimmed and/or turned off automatically. Technology use Infra-Red, } \\
\text { Ultrasonic waves or other. }\end{array}$ \\
\hline When to use it? & $\begin{array}{l}\text { Using this strategy can be effective in both buildings with variable } \\
\text { occupancy as well as in buildings with a rather predictable occupancy } \\
\text { pattern. } \\
\text { In spaces that are often used by different occupants for only a short } \\
\text { period of time (e.g. corridors and stairways, sanitary rooms,...), } \\
\text { presence detection might be effective to avoid that the occupant always } \\
\text { has to turn on the lighting manually and to prevent that the lighting stays } \\
\text { turned on after the occupant has left. }\end{array}$ \\
\hline $\begin{array}{l}\text { Aspects having } \\
\text { a major impact } \\
\text { on effective } \\
\text { performance of } \\
\text { the system }\end{array}$ & $\begin{array}{l}\text { - } \quad \text { Mode: presence or absence detection (this is a setting on the detector } \\
\text { most of the time) } \\
\text { - } \quad \text { Length of the delay time } \\
\text { - } \quad \text { Size of the zones that are controlled individually } \\
\text { (complete space controlled by one detector or a group of detectors, or } \\
\text { divided in separate zones?) }\end{array}$ \\
\hline Additional info & $\begin{array}{l}\text { - This type of automatic lighting control system is very robust and has a } \\
\text { rather low cost. }\end{array}$ \\
\hline
\end{tabular}




\begin{tabular}{|l|l|}
\hline & $-\quad \begin{array}{l}\text { From an energy point of view, presence detection is always less } \\
\text { advantageous than absence detection. }\end{array}$ \\
- & $\begin{array}{l}\text { Depending on the type of system, several functions are available: e.g., } \\
\text { length of the delay time, second delay time for orientation light, target } \\
\text { brightness level ... }\end{array}$ \\
\hline
\end{tabular}

\begin{tabular}{|c|c|}
\hline \multicolumn{2}{|c|}{ Variant 2 : absence detection } \\
\hline $\begin{array}{l}\text { How does it } \\
\text { work? }\end{array}$ & $\begin{array}{l}\text { The artificial lighting controlled by the detector is only turned on after it } \\
\text { has been switched on manually by an occupant, even if there was } \\
\text { already human activity in the space before. As long as human activity is } \\
\text { detected, the artificial lighting stays turned on. When the detector } \\
\text { doesn't detect any human activity during a predefined period (the } \\
\text { switch-off delay time), the artificial lighting is dimmed and/or turned off } \\
\text { automatically. }\end{array}$ \\
\hline When to use it? & $\begin{array}{l}\text { Using this strategy can be effective in both buildings with variable } \\
\text { occupancy as well as in buildings with a rather predictable occupancy } \\
\text { pattern. } \\
\text { In spaces where the artificial lighting isn't necessarily always turned on } \\
\text { during occupancy (e.g. because the daylight level is sufficient), absence } \\
\text { detection is preferred to presence detection. Generally, this is applicable } \\
\text { to spaces like office spaces, classrooms ... }\end{array}$ \\
\hline $\begin{array}{l}\text { Aspects having } \\
\text { a major impact } \\
\text { on effective } \\
\text { performance of } \\
\text { the system }\end{array}$ & $\begin{array}{l}\text { - Mode: presence or absence detection (this is a setting on the detector } \\
\text { - } \quad \text { Length of the delay time } \\
\text { - } \quad \text { Target brightness level (if function is available in the detector) } \\
\text { - Size of the zones that are controlled individually } \\
\text { (complete space controlled by one detector or a group of detectors, or } \\
\text { divided in separate zones?) }\end{array}$ \\
\hline Additional info & $\begin{array}{l}\text { - This type of automatic (or semi-automatic) lighting control system is } \\
\text { very robust and has a rather low cost. } \\
\text { - An absence detector has to be installed in combination with a manual } \\
\text { push button. } \\
\text { - From an energy point of view, absence detection is always more } \\
\text { advantageous than presence detection. } \\
\text { - Depending on the type of system, several functions are available: e.g., } \\
\text { length of the delay time, second delay time for orientation light, target } \\
\text { brightness level ... }\end{array}$ \\
\hline
\end{tabular}

- Daylight-control systems

Major purpose: $\quad$ Saving energy while maintaining the visual comfort of the users by adjusting the artificial light level depending on the amount of daylight available in the space. The lighting can be switched off, switched to a lower lighting level or dimmed down continuously as a function of the amount of daylight available at that moment.

\begin{tabular}{|l|l|}
\hline Variant 1 : open loop daylight-responsive control \\
\hline $\begin{array}{l}\text { How does it } \\
\text { work? }\end{array}$ & $\begin{array}{l}\text { Artificial lighting is controlled (switched off (completely/partially) or } \\
\text { dimmed) based on a measurement of only daylight: the sensor is } \\
\text { positioned in such a way that it doesn't detect the artificial lighting it is } \\
\text { controlling. The sensor can be placed inside, facing the window area, or } \\
\text { outside (usually on the roof or at the façade). As the system is } \\
\text { controlling the artificial lighting without getting feedback about the } \\
\text { resulting light level, the system is 'open loop'. }\end{array}$ \\
\hline When to use it? & $\begin{array}{l}\text { Open loop systems might be preferable to closed loop systems in } \\
\text { certain circumstances. However, there are no hard and fast rules about } \\
\text { when to use them. }\end{array}$ \\
\hline
\end{tabular}




\begin{tabular}{|l|c|}
\hline $\begin{array}{l}\text { Aspects having } \\
\text { a major impact } \\
\text { on effective } \\
\text { performance of } \\
\text { the system }\end{array}$ & $\begin{array}{l}\text { In general, it is worth applying daylight-responsive control in buildings } \\
\text { (/spaces) that receive a lot of daylight, but where the annual time the } \\
\text { artificial lighting is on is still considerably high. }\end{array}$ \\
\hline $\begin{array}{l}\text { Amount of daylight entering the building/space during the time the } \\
\text { artificial lighting is on (incl. presence \& usage of solar shading system) }\end{array}$ \\
$\begin{array}{l}\text { Time that the artificial lighting is on during daytime } \\
\text { - }\end{array}$ \\
$\begin{array}{l}\text { Type of daylight-responsive control system (switching off } \\
\text { (completely/partially) or dimming) }\end{array}$ \\
$\begin{array}{l}\text { Zone of luminaires that is controlled by the system (and the position } \\
\text { toward the daylight openings) (level of daylight decreases with the } \\
\text { distance from the daylight opening) } \\
\text { (absolute AND relative energy savings from the system will be different } \\
\text { if all luminaires of a space are controlled or if only the row of luminaires } \\
\text { at the window side is controlled). } \\
\text { Setting up the system correctly is extremely important for daylight- } \\
\text { responsive control systems to make sure that the effective } \\
\text { performance of the system is comparable to the theoretically attainable } \\
\text { performance (considering both energy savings and visual comfort). } \\
\text { Ideally, setting up the system is not a one-time-action, but a recurrent } \\
\text { process of evaluating and adjusting the set-up when needed. }\end{array}$ \\
\hline $\begin{array}{l}\text { If the system uses one or more outdoor sensors, its data can be used } \\
\text { for controlling the artificial lighting of all spaces of a façade, or even of } \\
\text { the whole building. } \\
\text { If the system uses an outdoor sensor, the system must be able to } \\
\text { interact with the shading system, or the system could be used to } \\
\text { control both artificial lighting and solar shading. } \\
\text { Dimming daylight-responsive control is preferable to switching daylight- } \\
\text { responsive control as it has much less potential for disrupting } \\
\text { occupants (comfort requirements). Besides, from an energy point of } \\
\text { view, dimming systems would often be more advantageous than } \\
\text { switching systems. }\end{array}$ \\
\hline
\end{tabular}

\section{Variant 2 : closed loop daylight-responsive control}

\begin{tabular}{|l|l|}
\hline $\begin{array}{l}\text { How does it } \\
\text { work? }\end{array}$ & $\begin{array}{l}\text { Artificial lighting is controlled (switched off (completely/partially) or } \\
\text { dimmed) based on a measurement of the combination daylight and the } \\
\text { artificial light it is controlling. The sensor(s) carrying out the } \\
\text { measurement are usually oriented towards the task area where the } \\
\text { artificial light is meant to fall. As the system continuously receives } \\
\text { feedback about the artificial lighting it is controlling, the system is } \\
\text { 'closed loop'. }\end{array}$ \\
\hline When to use it? & $\begin{array}{l}\text { Closed loop systems might be preferable to open loop systems in } \\
\text { certain circumstances. However, there are no hard and fast rules about } \\
\text { when to use them. } \\
\text { In general, it is worth applying daylight-responsive control in buildings } \\
\text { (/spaces) that receive a lot of daylight, but where the annual time the } \\
\text { artificial lighting is on is still considerably high. }\end{array}$ \\
\hline $\begin{array}{l}\text { Aspects having } \\
\text { a major impact } \\
\text { on effective } \\
\text { performance of } \\
\text { the system }\end{array}$ & $\begin{array}{l}\text { Amount of daylight entering the building/space during the time the } \\
\text { artificial lighting is on (incl. presence \& usage of solar shading system) }\end{array}$ \\
$-\begin{array}{l}\text { Time that the artificial lighting is on during daytime } \\
\text { Type of daylight-responsive control system (switching off } \\
\text { (completely/partially) or dimming) }\end{array}$ \\
$\begin{array}{l}\text { Zone of luminaires that is controlled by the system (and the position } \\
\text { toward the daylight openings) (level of daylight decreases with the } \\
\text { distance from the daylight opening) } \\
\text { (Absolute AND relative energy savings from the system will be different } \\
\text { if all luminaires of a space are controlled or if only the row of luminaires } \\
\text { at the window side is controlled). } \\
\text { Setting up the system correctly is extremely important for daylight- } \\
\text { responsive control systems to make sure that the effective } \\
\text { performance of the system is comparable to the theoretically attainable }\end{array}$ \\
\hline
\end{tabular}




\begin{tabular}{|l|l|}
\hline & $\begin{array}{l}\text { performance (considering both energy savings and visual comfort). } \\
\text { ldeally, setting up the system is not a one-time-action, but a recurrent } \\
\text { process of evaluating and adjusting the set-up when needed. }\end{array}$ \\
\hline Additional info & $-\begin{array}{l}\text { Sensors of a closed loop daylight-responsive control system are } \\
\text { obviously placed indoor, mostly one or more sensors per space (as } \\
\text { there is a direct link between the measurement of the sensor(s) and } \\
\text { the light on the task area). Depending on the type of system, there is } \\
\text { one sensor per space / per (x) row(s) of luminaires parallel to the } \\
\text { window side / per luminaire. } \\
\text { Dimming daylight-responsive control is preferable to switching daylight- } \\
\text { responsive control as it has much less potential for disrupting } \\
\text { occupants (comfort requirements). Besides, from an energy point of } \\
\text { view, dimming systems would often be more advantageous than } \\
\text { switching systems. }\end{array}$ \\
\hline
\end{tabular}

- Constant light output (CLO), or luminous flux depreciation compensation

Major purpose: $\quad$ Saving energy while maintaining the visual comfort of the users by dimming the artificial lighting to a constant light level over its lifetime, compensating the over-dimensioning for the expected future light depreciation (deepest dimming values after installation; no dimming at the end of the lifetime of the installation).

\begin{tabular}{|l|l|}
\hline Variant 1 : constant light output programmed on the driver \\
\hline $\begin{array}{l}\text { How does it } \\
\text { work? }\end{array}$ & $\begin{array}{l}\text { The system anticipates future depreciation of light output of the artificial } \\
\text { lighting installation. Thus, the system dims the artificial lighting to a } \\
\text { constant light level over its lifetime, compensating the over- } \\
\text { dimensioning for the expected future light depreciation (deepest } \\
\text { dimming values after installation; no dimming at the end of the lifetime } \\
\text { of the installation). }\end{array}$ \\
\hline When to use it? & $\begin{array}{l}\text { As lighting installations are initially always over-dimensioned, as the } \\
\text { minimum light level at the end of the lifetime (after light depreciation) } \\
\text { should still be maintained, applying CLO is advisable whenever it is } \\
\text { possible. It can increase the energy savings potential during the first } \\
\text { years after installation significantly. } \\
\text { To apply CLO programmed on the driver, the driver should be } \\
\text { programmable and the light output depreciation curve of the led } \\
\text { luminaire should be known (it is assumed that the lighting installation } \\
\text { uses led technology). }\end{array}$ \\
\hline $\begin{array}{l}\text { Aspects having } \\
\text { a major impact } \\
\text { on effective } \\
\text { performance of } \\
\text { the system }\end{array}$ & $\begin{array}{c}\text { Light output depreciation curve of the led luminaire } \\
\text { Degree of over-dimensioning of the artificial lighting installation } \\
\text { Additional info }\end{array}$ \\
\hline
\end{tabular}

\section{Variant 2 : constant light output using light sensors}

\begin{tabular}{|l|l|}
\hline $\begin{array}{l}\text { How does it } \\
\text { work? }\end{array}$ & $\begin{array}{l}\text { Systems using a sensor that measures the artificial light it is controlling, } \\
\text { allow to control and stabilize the light output. Thus, the system dims the } \\
\text { artificial lighting to a constant light level over its lifetime, compensating } \\
\text { the over-dimensioning for the expected future light depreciation } \\
\text { (deepest dimming values after installation; no dimming at the end of the } \\
\text { lifetime of the installation). }\end{array}$ \\
\hline When to use it? & $\begin{array}{l}\text { As lighting installations are initially always over-dimensioned, as the } \\
\text { minimum light level at the end of the lifetime (after light depreciation) } \\
\text { should still be maintained, applying CLO is advisable whenever it is } \\
\text { possible. It can increase the energy savings potential during the first } \\
\text { years after installation significantly. }\end{array}$ \\
\hline
\end{tabular}




\begin{tabular}{|l|c|}
\hline & $\begin{array}{l}\text { CLO using light sensors is applied automatically for luminaires which } \\
\text { are controlled by a closed loop daylight-responsive control system. }\end{array}$ \\
\hline $\begin{array}{l}\text { Aspects having } \\
\text { a major impact } \\
\text { on effective } \\
\begin{array}{l}\text { performance of } \\
\text { the system }\end{array}\end{array}$ & $-\quad \begin{array}{l}\text { Reliability and accuracy of the dimming system over time } \\
\text { Setting up the system correctly is extremely important }\end{array}$ \\
\hline Additional info & $/$ \\
\hline
\end{tabular}

- (Load shedding, or demand response) :

Major purpose: $\quad$ Shaving peak demand or responding to a utility price or demand response signal by shedding lighting loads dynamically (through dimming or switching).

\begin{tabular}{|l|c|}
\hline \multicolumn{2}{|l|}{ Variant 1: load shedding, or demand response } \\
\hline $\begin{array}{l}\text { How does it } \\
\text { work? }\end{array}$ & Automatic reduction of energy demand by an external signal \\
\hline When to use it? & $\begin{array}{l}\text { In areas where tariffs of electricity varies greatly according to time of } \\
\text { day and in buildings where power can be reduced for specific periods }\end{array}$ \\
\hline $\begin{array}{l}\text { Aspects having } \\
\text { a major impact } \\
\text { on effective } \\
\text { performance of } \\
\text { the system }\end{array}$ & $\begin{array}{l}\text { The reduction of power should be accepted by the occupants meaning } \\
\text { that this strategy is appropriate for general lighting, but not for task } \\
\text { related lighting (specific work or displays). }\end{array}$ \\
\hline Additional info & $-\begin{array}{l}\text { Dimming strategies are preferable to switching strategies as they have } \\
\text { much less potential for disrupting occupants (comfort requirements). }\end{array}$ \\
\hline
\end{tabular}

\subsection{Points of attention / concerns to be considered}

To get more in-depth information about the different type of electric lighting controls and about which type of controls would be appropriate in certain circumstances, reference is made to the CIE document 'CIE 222-2017 : Decision Scheme for Lighting Controls in Non-Residential Buildings'. This document offers guidelines in order to balance lighting quality, user comfort and energy efficiency in lighting controls solutions for lighting in nonresidential buildings. It lists the different types of lighting control systems that exist for lighting in non-residential buildings. It provides a decision scheme with a focus on the user requirements (visual comfort, performance, personal control) to determine the most applicable control solution, including the consequences for possible savings.

It is obvious that there is not necessarily one specific lighting control system that yields up the complete solution in a certain situation. Most of the time, combining several lighting control systems together results in the most effective solution. The systems are sometimes equipped with different physical components, but they can also be assembled into one fitting. A typical example is a detector combining occupancy detection with daylight responsive control.
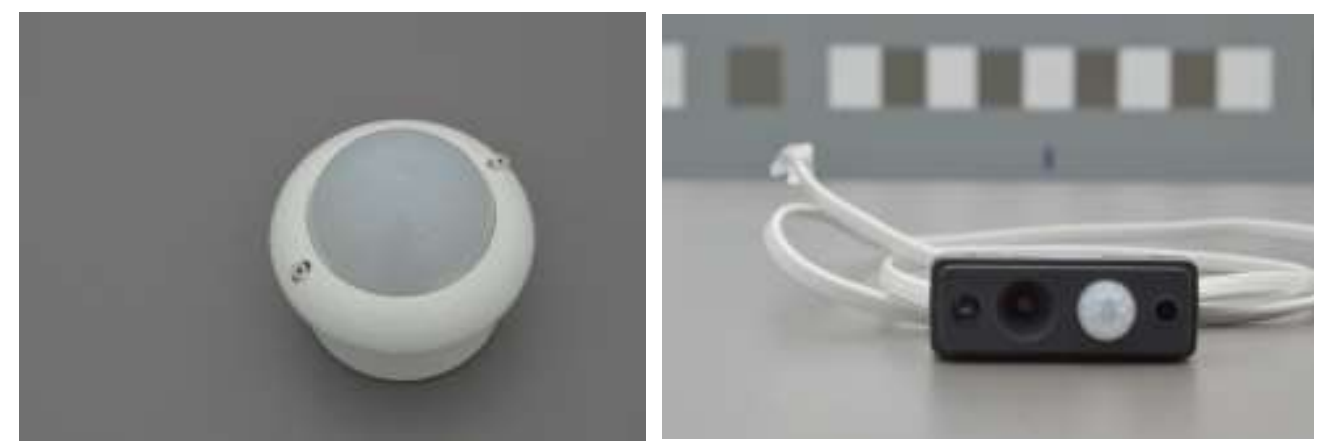

Figure 18. Examples of detectors combining occupancy detection with daylight responsive control in one fitting. 
The following principles should always be considered when designing and implementing the lighting control systems of a lighting installation and yet they are very often forgotten:

- $\quad$ Lighting controls are not something 'separate'. They interact with both daylight $(\rightarrow$ daylight openings and solar shading) and artificial lighting. Daylight penetration in the building should be allowed in a wellconsidered way. Additionally, the artificial lighting should make use of an energy efficient technology. Nowadays, LED lighting is the standard, as it is can provide very qualitative light in a very energy efficient way. Finally, lighting control systems can contribute to limit the use of the artificial lighting (in time, in active power (dimming, ...).

- It is useful to always consider dividing the lighting in separate zones. It ensures that lighting is only used at the places where it is needed. Zoning the lighting installation in a logical way can result in substantially increased energy savings.

- $\quad$ Not only proper installation (positioning of sensors, wiring,...), but also setting up the (automatic) control systems correctly is extremely important to make sure that the effective performance of the system is comparable to the theoretically attainable performance (considering both energy savings and visual comfort). Ideally, setting up the system is not a one-time-action, but a recurrent process of evaluating and adjusting the set-up when needed (long-term commissioning).

- Automatic lighting control is an essential component of a strategy aiming to reduce electric lighting consumption while still providing the desired visual comfort to the users. However, giving users personal control over the automatic lighting installation by equipping the installation additionally with manual lighting controls has a positive effect on their comfort, satisfaction and performance.

- Moreover, it is very important to engage the users of the building in the design process and the actual implementation of lighting control systems. The needs of the users have to be understood and taken into account. Besides, the users should be informed regularly. At the one hand, they need to know how to use the manual control systems, at the other hand it's also important for them to know which automatic control systems were implemented and how they function. That way, the level of acceptance of the users towards the automation will raise significantly. Besides, it is more likely that they will report potential problems rather than trying to solve the problems themselves (which is often equal to disrupting the system).

This chapter has focused on the existing types of electric lighting control systems, what their major purpose is and what has to be taken into account when considering implementation of these systems.

However, since the 'Ledification' and together with that the digitization of lighting, radical changes took place in how the different components of the artificial lighting installation communicate. Lighting control communication can be both wired as well as wireless. The next chapter aims to give an overview of the most important communication protocols that are used in lighting control nowadays.

\subsection{Issues concerning sensor placement}

The ratio of daylight to artificial light should be maximized with proper sensor placement, while not being exposed to sunlight sunlight. Therefore, sensors should not be placed in direct sunlight in the space. This might cause the readings of the sensor to be off and the system not to operate properly.

As a rule of thumb, the daylight sensors should be placed at a distance from the nearest windows of one or two times the effective window height. The effective window height stands for either starting at the window sill or $1 \mathrm{~m}$ up from the floor (whichever is higher) and ending at the top of the window

In case of partitioned spaces such as private offices, one sensor should be allocated for each space in order to meet the expectations of each individual and to prevent the conflicts between users. In case of an open office, one sensor should be placed at least every 30 linear feet of window wall [Lutron Sensor Placement Guidelines]. 


\section{Lighting Control Protocols}

\subsection{Introduction: Wired / Wireless}

Beside traditional Building Automation Systems (like EIB/KNX/BACnet - see above) since the year 2000 different new approaches and technologies have been brought to the market. There are two main approaches to be considered. Wireless Systems, which are powered via the wires, but receive and send their commands via radio (e.g. WLAN) and wired Systems, which are driven and controlled via wires from a central power and control unit e.g. DALI Power over Ethernet).

\subsection{Wired systems}

Wired lighting control systems have evolved through the time, since the beginning of the invention of electricity and the light bulb. Most of the lighting till today is simply switched on or off (mostly remotely), without any dimming function.

Since Dimming allows to create smoother and more comfortable environments, but also gives the possibility to save energy, it can be seen as the first step into what we call "smart homes" today. We are able to divide two main groups, which might be well known from other technologies like Music or Photography. One is analogue, the other is digital.

\subsection{Wired Systems / Analogue}

Analogue dimming covers all dimming systems that don't transform the dimming signal into bits but controls the lighting in analogue manner. The most common systems are quite well established in the market, mostly in residential buildings.

Phase dimming systems dim the lights by altering the supply voltage. It works with the well-known Edison Light Bulb and most of the Halogen Bulbs, but does not dim Fluorescent Lamps or LED Retrofit Lamps reliable.

Leading \& trailing edge dimming: before LEDs, halogen lamps were dimmed with wall mounted either leading or trailing edge dimmers. These can still be used, but dimmer, driver and LED-module must be compatible with each other. This type of control is accomplished without any need for an additional control wire. It involves connecting a dimmer in series between one of the mains wire and the equipment. The dimmer cuts part of the mains voltage sinusoidal waveform to a greater or lesser extent in order to dim luminous flux even from $1 \%$ to $100 \%$ (this value depends on dimmer and driver).

Depending on how the driver makes the mains voltage cut, it is possible to distinguish between two types of dimming. Leading-edge- and Trailing-edge dimming, causes less interferences than leading-edge dimming because of the cut-off in the wave on its descending side (cutting the end from backwards).

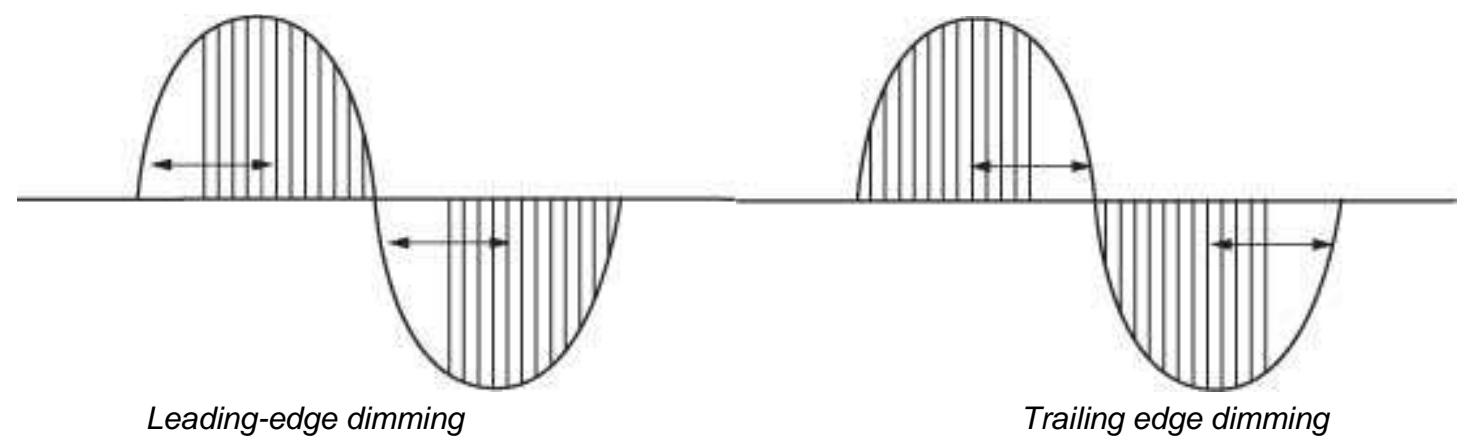

Figure 19: Leading and trailing edge dimming 
There are dimmers and equipment that support both types of dimming, and others that support only one type.

\subsubsection{1-10V dimming}

The 1-10V system enables dimming of the luminous flux from around $1 \ldots 10 \%$ to $100 \%$. This is done by sending an analogue signal to the equipment over an additional, two-wire control line. These control wires have positive and negative polarities respectively and that must be kept in mind when wiring up the system.

International standard, IEC 60929, defines the dimming curve. The dimming curve represents the relationship between the control line voltage and the luminous flux. It reflects a practically linear relationship in the range of $3 \mathrm{~V}$ to $10 \mathrm{~V}$.

To get a response adapted to that of the human eye it is possible to use logarithmically controlled potentiometers.

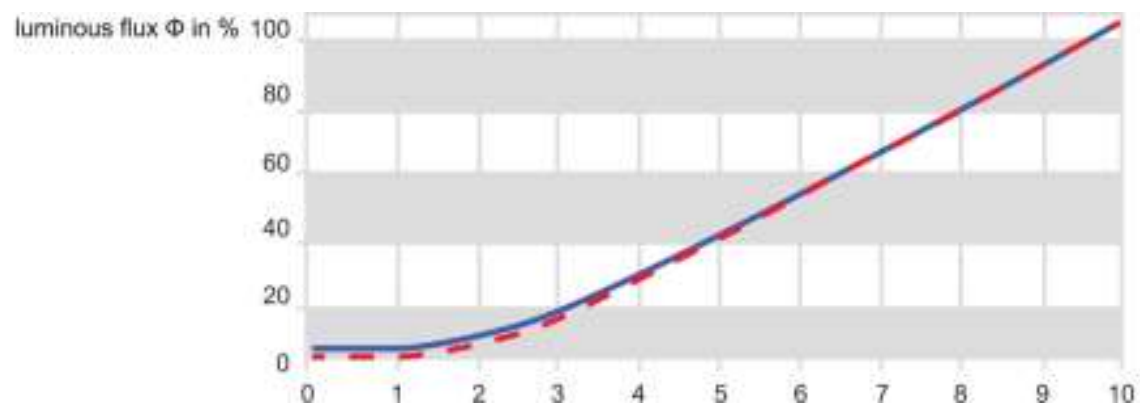

Figure 20. Regulation curve by IEC 60929.

This dimming system is unidirectional, i.e. the information flows in one direction, from the controller to the light fixture. The latter generates no feedback to control. Groups have to be created by wiring. This system can be integrated into building control systems.

The voltage drop in the control line wiring limits its length. Therefore, the maximum distance is limited by the number of control gears connected. The latter establishes the current per line and the cable diameter used.

\subsubsection{Touch Control Push Button (analogue but can be connected to digital systems)}

Touch Control is a system that enables simple and economic dimming of luminous flux. It uses the mains voltage as a control signal, applying it with a standard push button on a control line, without any need for specific controllers.

The Touch Control system enables to carry out the basic functions of a dimming system with a pushbutton which do not require power supply.. Depending on how long the button is pressed it is possible to switch the light on or off or dim it. Switching the light on or off is done by short, sharp pressing or "click". If the button is pressed for a long time it is possible to dim or increase the luminous flux between the maximum and minimum levels alternately.

\subsection{Wired Systems / Digital}

Digital dimming covers all dimming systems that transform the dimming signal into bits and controls the lighting in digital format.

\subsubsection{DALI (digital)}

As revealed by the meaning of its acronym, Digital Addressable Lighting Interface, DALI is a digital and addressable communication interface for lighting systems. It is an international standard system in accordance with IEC 62386, which ensures compatibility and interchangeability between different manufacturers products marked with the following logo: 


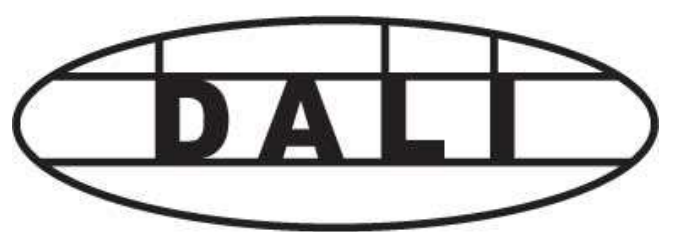

Figure 21. DALI-logo.

It is a bi-directional dimming interface with a master-slave structure. The information flows from a controller, which operates as the master, to the control gears that only operate as slaves. The latter carries out the commands or respond to the information requests received.

Digital signals are transmitted over a bus or two-wire control wire. These control wires can be negatively and positively polarized, though the majority control gears are designed polarity free to make connection indifferent.

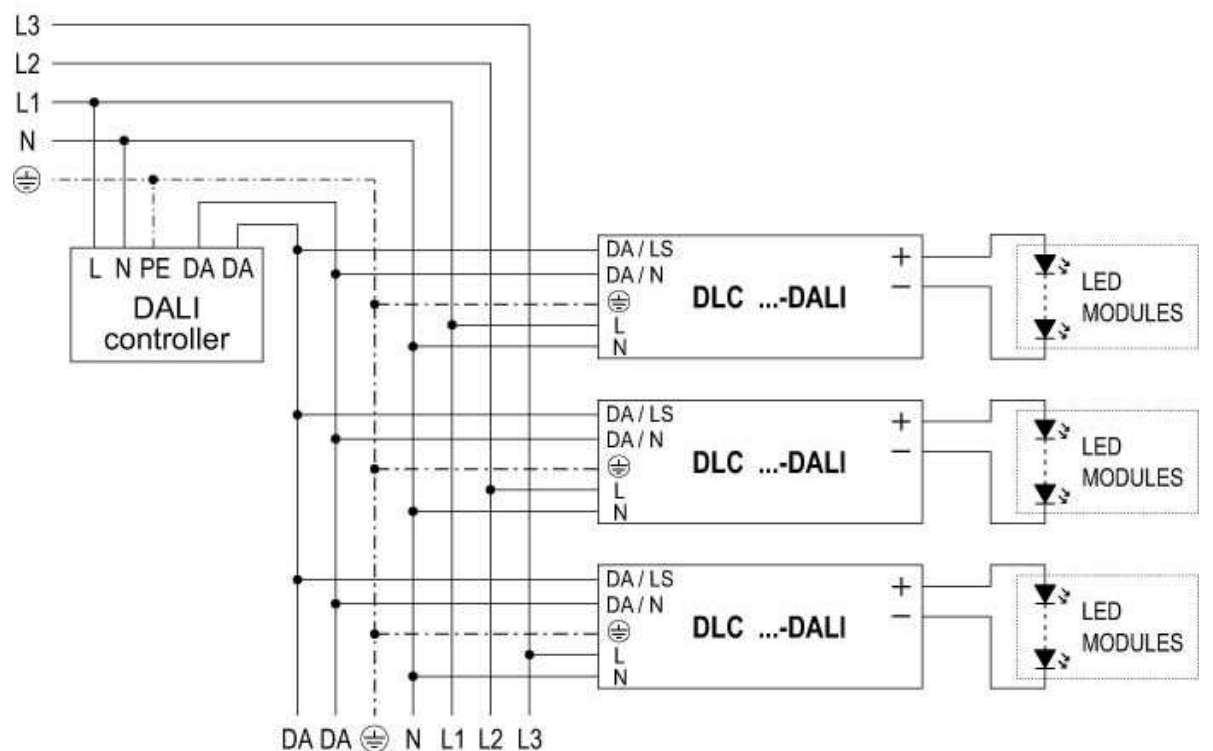

Figure 22. DALI Dimming.

Unlike other systems, you don't need to create wiring groups. Therefore all the pieces of fixtures are connected in parallel to the bus. Without bearing in mind the grouping of these, simply avoiding a closed ring or loop topology.

No mechanical relays to switch the lighting on or off are needed, given that this is obtained by commands sent along the control line. You don't need bus termination resistors either.

The maximum voltage drop along the control line must not exceed $2 \mathrm{~V}$ with the maximum bus current of $250 \mathrm{~mA}$. Therefore, the maximum wiring distance allowed depends on the cable cross-section, but it must never exceed $300 \mathrm{~m}$ in any case.

\subsubsection{Configuring the DALI system}

After wiring, the DALI lighting system is configured with the software. You can create up to 16 different scenarios, addressing the equipment individually up to a maximum of 64 addresses. This can be made with groups up to a maximum of 16 , or simultaneously by means of a "broadcast" order. You can change the configuration at any time without any need for re-wiring.

The DALI system has a logarithmic regulation curve adjusted to human eye sensitivity, defined in the international standard, IEC 62386 . The possible dimming range is set at from $0.1 \%$ to $100 \%$. The driver manufacturer determines the minimum. 


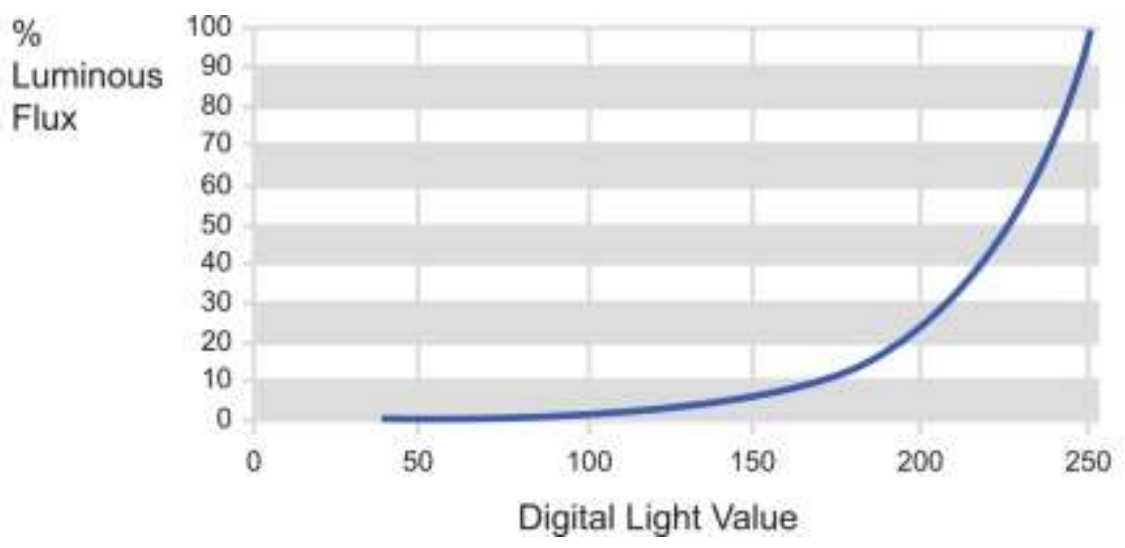

Figure 23. DALI Regulation Curve by IEC 62386.

With the software, you can change the "fade rate". "Fade rate" is the time needed to go from one light level to another (fade time) and the speed of the change.

\subsubsection{DALI with Touch dimming}

You can use this interface in simple applications independently, to control a luminaire or a small room. You can also use it in high-level applications such as being integrated by gateways into building smart control systems.

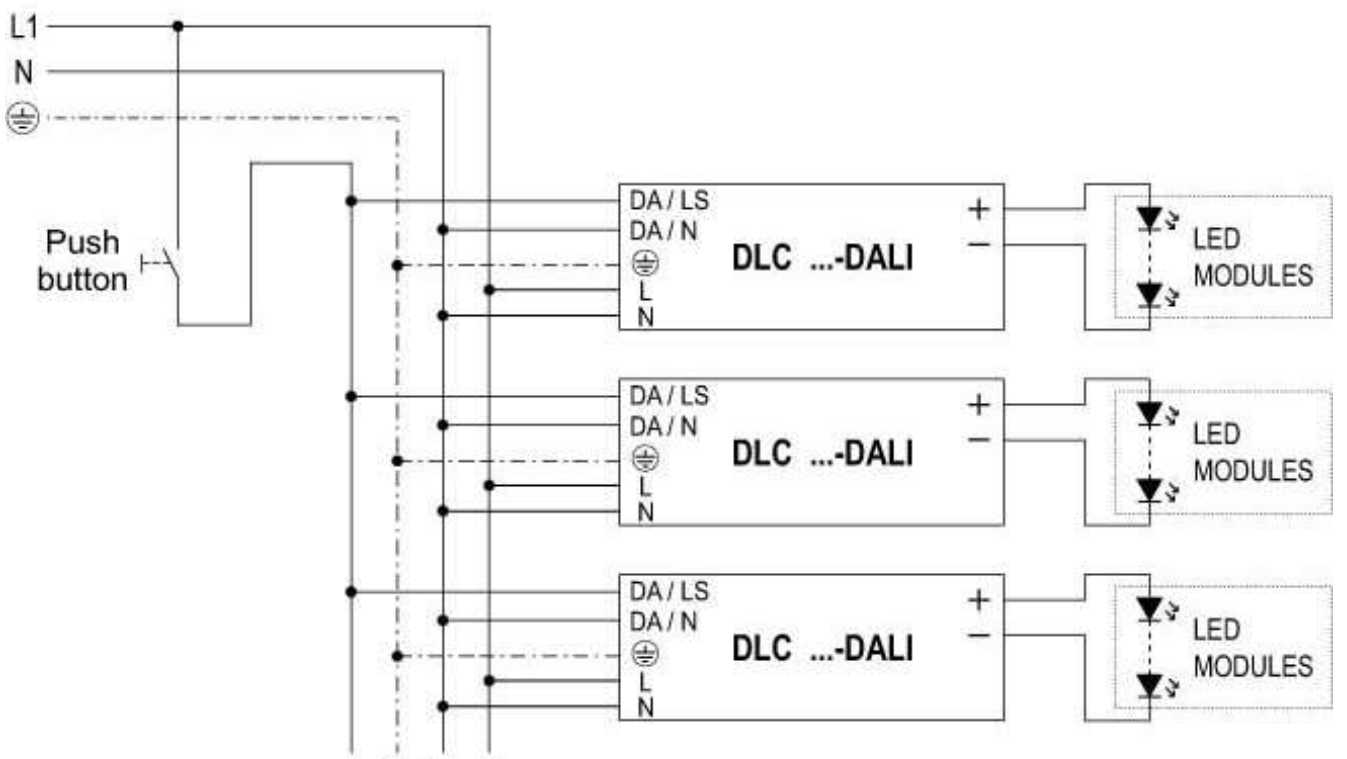

Ls $\triangleq$ N L1

Figure 24. Touch Dimming.

This is a unidirectional interface, i.e. information flows in one direction. The equipment does not generate any type of feedback. Groups have to be created by wiring. This system cannot be integrated into building control systems.

The length of the wiring and the number of equipment that can be connected, are theoretically unlimited. But in, asynchronism may occur during switching on and dimming, at distances longer than 25 meters, and with a larger number of fixtures connected.

Owing to its characteristics, the use of this dimming method is recommended for individual offices, small meeting rooms or bedrooms, landings and small spaces in general. 


\subsubsection{KNX}

KNX applies through the enhancements to configuration mechanisms and transmission media as a further development of the EIB bus including the fieldbuses BatiBus and EHS. Even the proximity and compatibility with the European Installation Bus (EIB) makes it clear that it is primarily a system for the entire building management. Meanwhile, interesting solutions for the light and in particular the LED technology are available, but these special tasks are often realized via gateways and other protocols such as DALI or DMX. KNX is also an open standard to which several hundred manufacturers have already joined. The resulting extensive range of possible solutions makes the system diverse and interesting.

\section{Fundamentals of KNX technology}

Usually, a power grid consists of parallel or series-connected elements of the control and supply. With the KNX network, all devices use the same transmission method and data is exchanged over a common bus line. Thus, in the basic version, an additional line with $29 \mathrm{~V}$ DC voltage is laid, which provides the power supply for the communication between the sensors and actuators.

Meanwhile, radio solutions (RF), transmissions over Ethernet (IP) and the Power Line System (PL), which uses the existing power grid, are also possible. The origin and also the most reliable variant is the twisted pair (TP) solution, which works with an additional control cable. The structure of a KNX network is always similar: before the actual devices, corresponding actuators are set, which are addressed by the sensors in the system or centrally by a control unit / a computer.

Several suppliers offer Luminaire Drivers, which are able to be controlled via KNX directly, which allows to save costs for DALI Gateways and reduction of software variety.

\subsubsection{DMX}

In stage and event technology, the digital DMX protocol (Digital Multiplex) is the standard par excellence when it comes to controlling dimmers, "intelligent" headlamps, moving heads and effect units. In principle, DMX systems can also be used in permanently installed architectural lighting - but with advantages and disadvantages.

DMX512 (Digital Multiplex) is a standard for digital communication networks that are commonly used to control stage lighting and effects. It was originally intended as a standardized method for controlling light dimmers, which, prior to DMX512, had used various incompatible proprietary protocols. It soon became the primary method for linking controllers (such as a lighting console) to dimmers and special effects devices such as fog machines and intelligent lights. DMX has also expanded to be used in non-theatrical interior and architectural lighting, at scales ranging from strings of Christmas lights to electronic billboards. DMX can now be used to control a large variety of systems, reflecting its popularity in theaters and venues.

DMX512 employs EIA-485 differential signaling at its physical layer, in conjunction with a variable-size, packetbased communication protocol. It is unidirectional.

DMX512 does not include automatic error checking and correction, and so is not an appropriate control for hazardous applications such as pyrotechnics or movement of theatrical rigging. False triggering may be caused by electromagnetic interference, static electricity discharges, improper cable termination, excessively long cables, or poor quality cables. (Wikipedia)

\subsubsection{Powerline / "Ready2mains"}

This technology has been brought to the market by Tridonic and can be seen as an example for various "closed systems". The associated Drivers must be equipped with ready2mains functionality. The interface between the control unit and the luminaires needs to be a ready2mains gateway which transmits the dimming commands in digital form via the mains cable ensuring reliable and robust data transmission.

There is no need for any additional data cables such as DALI/DSI systems.

Conventional pushbuttons can be used as the control units, and sensors for detecting presence or daylight, for example, can be easily integrated. Integration in a DALI network is also possible via the one4all (Tridonic) interface at the gateway. The interface also adds DALI, DSI, switch DIM and corridor FUNCTION functionality. 
A single control unit is capable of controlling or dimming all the connected luminaires in a room. Multiple control units or gateways can be used in parallel, if required. The total connected load of a gateway in the ceiling installation housing is 400 VA so up to 15 LED luminaires with ready2mains functionality can be connected. The maximum cable length is $250 \mathrm{~m}$.

\subsubsection{POE: Power over Ethernet}

So called Power over Ethernet (PoE) Systems have increased in the market, since the LED was introduced into the architectural lighting. Due to low Voltage and less power consumptions, Ethernet wiring is able to be used for lighting issues (up to $57 \mathrm{~V}$ and $44 \mathrm{~mA}$ ), including sensors and control functions. One big advantage is the very low danger in the installation; it can be compared to a traditional computer network, which is connected to a big server rack and could be done easily by the user itself or the facility management. Another advantage is the possibility of controlling and evaluating via software.

Beside this advantage the limited length of the wiring and the closed ecosystems need to be considered.

Although this is indeed true (it can be done by everybody) the installation of PoE is (should be) HD60364-series. It is identified that there is no legislation covering the Poe installations, which is why there is now a working group under IEC TC64, ELECTRICAL INSTALLATIONS AND PROTECTION AGAINST ELECTRIC SHOCK.

PoE technology allows direct current (DC) electrical power and data to be carried together on a Cat 5 (or higher) twisted pair cable. PoE was first used for Voice over Internet Protocol (VoIP) systems. In 2000, Cisco introduced a proprietary technology that allowed Ethernet cables to transmit 48 volts of DC supply to VoIP phones. Other companies followed, and soon PoE was commonly used in office VolP systems.

In 2003, the Institute of Electrical and Electronics Engineers (IEEE) released a standard for PoE. This was updated in 2009 with a standard that could carry more power. The result was that a single RJ45 connector and Cat 5 cable were capable of transmitting 30 watts of power.

Ultra PoE is a non-standardized version that supplies up to 60 watts of power, and soon a 100-watt PoE version will be available. As the available power increases, PoE lighting will become attractive to a greater number of customers.

PoE lighting systems only work with Light Emitting Diodes (LEDs). With PoE lighting, the lights connect to the IT system in the building. When combined with sensors and small processors that can make decisions about lighting, these systems can provide additional energy savings. A PoE lighting system can, for example, be configured to light only areas with occupants.

The power capacity is a critical feature of PoE lighting since each cable can carry only 60 watts of power. For delivery to a large building, zone cabling can be a good option. In a zoned cable system, consolidation points act as hubs from which the cabling delivers lighting, internet, and other loT services.

Another design consideration is whether to use a centralized or distributed approach. A centralized system in which all PoE switches are located in a central hub is the more common approach, but it requires a lot of cabling, and the cables are limited to a length of 100 meters.

A distributed system uses smaller switches set up in each zone. This requires less cable and removes the cable length limitations, but maintenance and repairs are challenging. In a distributed system, switches will need to be maintained throughout the building instead of in one central control room.

\subsubsection{Toward a DC power supply in ceilings of buildings}

A complementary approach deals with the suppression of all AC/DC voltage converters located at each luminaire source, and to distribute power through DC network, more precisely $48 \mathrm{~V}$ since it is a growing standard in electrical cars, and the maximum voltage which can be used by installers without specific certification of staff.

In this approach, the global energy efficiency of luminaires can be improved, since the efficiency of centralized $\mathrm{AC} / \mathrm{DC}$ converters (power range of $500 \mathrm{~W}$ to $2 \mathrm{KW}$ ) is higher (95\%) than the AC/DC drivers in LED luminaires 
converter of lamps (75\%). Supply of power can be done with RJ45 $(0.1 \mathrm{~mm} 2)$ data connectors ( $\max 100 \mathrm{~W}$ per line) or dedicated $48 \mathrm{~V}$ Wieland connectors for instance $0.4 \mathrm{~mm} 2$, higher power)

Power losses in DC cables are typically around $5 \%$ in $48 \mathrm{~V}$.

Such solutions have a general advantage of allowing easy connection by non-certified electricians, saving time and money when installing ceiling systems.

Electric power is distributed from centralized power supplies every 100 or $200 \mathrm{~m}^{2}$ of office space.

Another advantage of the $48 \mathrm{~V}$ approach stands in the capacity to integrate the architecture in a global DC network, including solar panels and batteries.

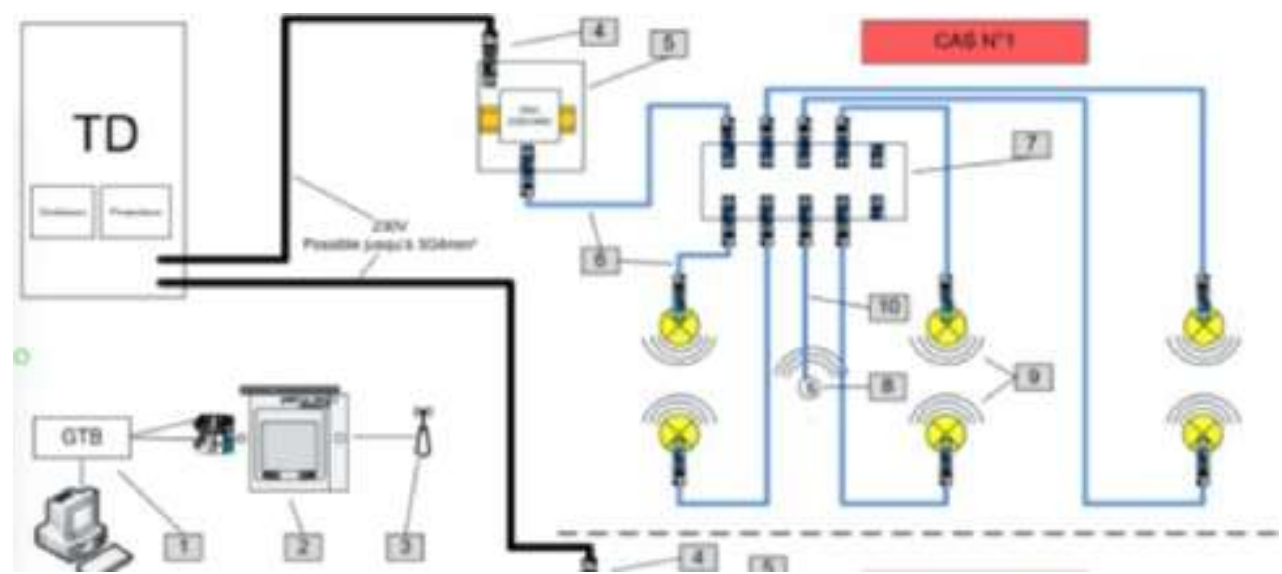

Figure 25. Example of DC power architecture for lamps and sensors, with Bluetooth communication (Source: Luxendi).

\subsubsection{Power issues}

PoE lighting can save up to $33 \%$ in energy costs, and proponents of PoE argue that the power supply is more reliable. But it's not that simple. For one thing, category cables have a lot of voltage drop unless six of eight conductors carry power and only two carry data. As well, there is significant power loss over distance with DC power.

When standard lighting has a power outage, the lights return immediately when power is restored. With PoE lighting, a system reboot may be required to get the lights back in operation network integrity is of paramount importance. Customers might be able to survive without internet for a few hours or days, but functioning without lights is more difficult. One way around this is to install a battery backup for the switches.

Another issue is interference. There are no problems running DC on a shared line with data, but the lighting circuitry could create electrical noise that interferes with internet service.

Users need to be aware, also, that any change in their lighting will require extra care. Only equipment that is compatible with their system can be used

\subsection{Wireless Systems}

Wireless systems do have one big advantage, which is the flexibility of addressing and relocating them. Due to the growing complexity of buildings more and more flexibility is needed by the planners and building owners, as decisions concerning the usage of the building are often revised in late states of the process. Also functions, which are not defined in the beginning of the building process, are sometimes only taken into account, after finishing first buildings steps. Here wireless systems help to implement technical solutions without heavy impact on the building site, evolving dirt, time and costs. Of course beside the sensors you usually have to install the needed infrastructure like routers or gateways, and connect them to your traditional Building Automation System, if you do not control your building just via the wireless infrastructure. 
As there are many different technologies and even more companies on the market, it is not always easy to take decisions on appropriate solutions. Beside router controlled Solutions, like ZigBee, Z-Wave and EnOcean, there are also Solutions based on Bluetooth, which can be installed and controlled without router or gateway. At the moment these solutions do not have the performance and scalability, but are even easier to be run on special solutions e.g. if you do only want to control the luminaires in a special part of your building and no interaction with shading, heating or cooling is needed.

\subsubsection{Wireless Lighting Control Systems and various types of wireless protocols}

Since the LED was introduced to the architectural lighting market in 2006, lighting became more and more digital and flexible. Due to the growing smart home and loT applications, wireless control has become a strong growing, but very confusing topic as a lot of new technologies, companies and radio controlled applications have been brought to the strong growing market.

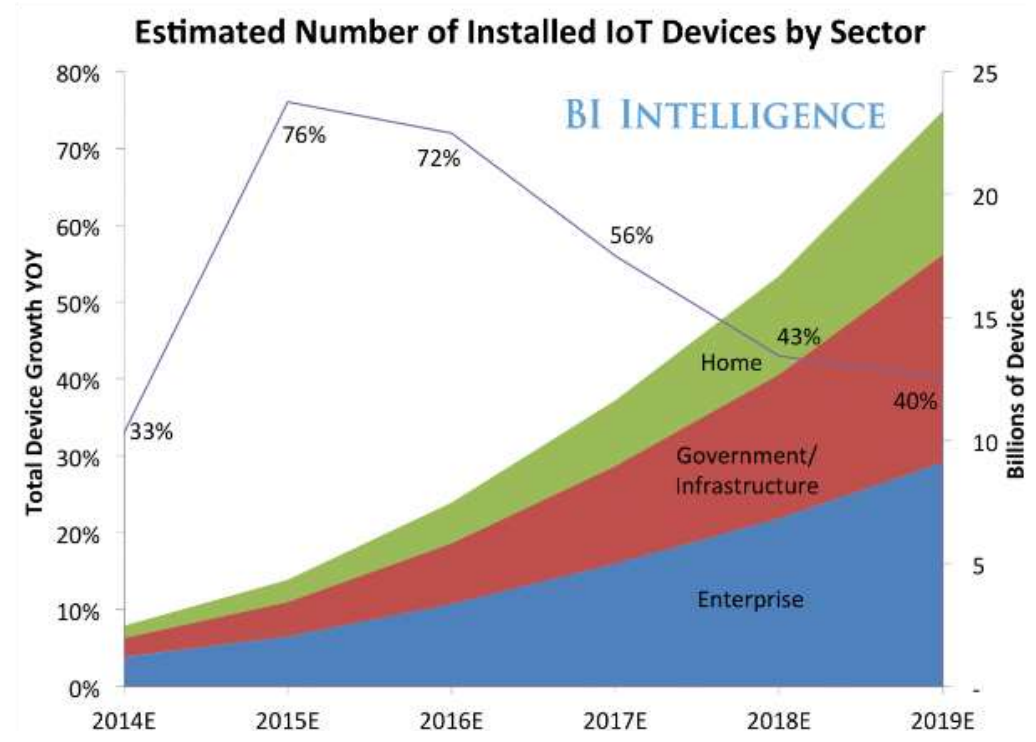

Figure 26. Source: BI Intelligence Estimates.

Unfortunately, this has led to various legislations on the radio frequencies in each part of the world, which make it even harder for global players, to implement new products or standards.

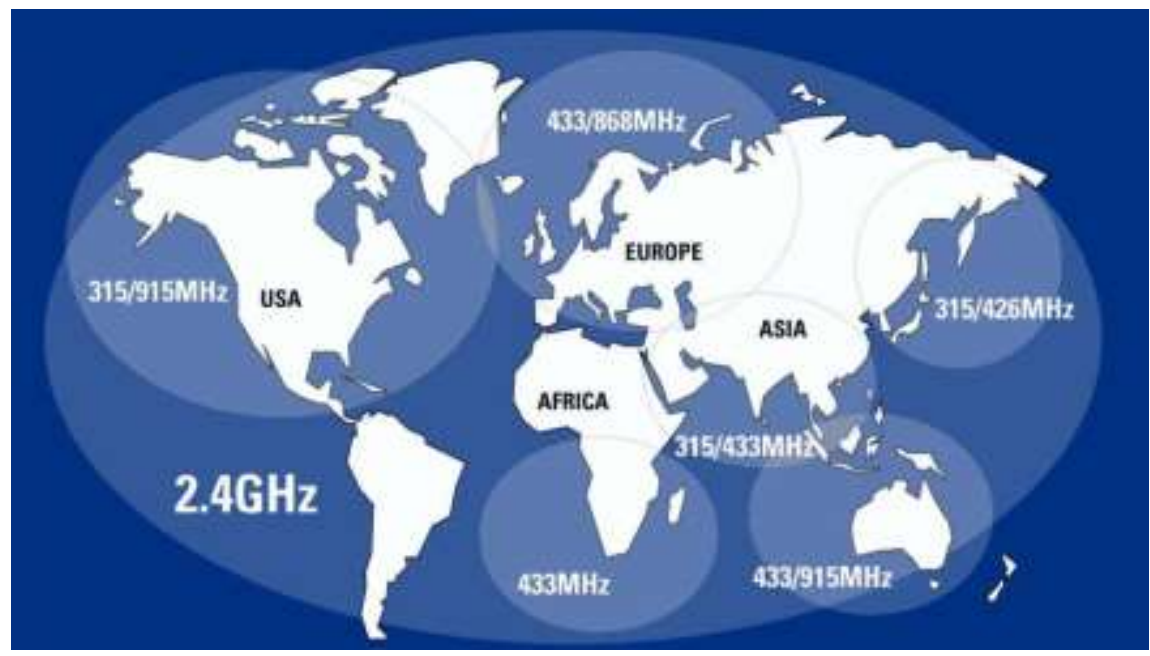

Figure 27. Source: https://predictabledesigns.com/most-important-decision-when-creating-wireless-product.

Beside the radio frequencies many technical aspects need to be considered, when comparing wireless control systems. Besides the Data rate (which goes from Kilobits per Second (kbit/s) up to Mega- and Gigabits per Second (Mbit/s)), and the Frequency (which is usually between $900 \mathrm{MHz}$ and $2400 \mathrm{MHz}$ ), also the Sensitivity, 
Transmitting Power, Energy Consumption and other parameters can play a role in the decision making, depending on the needs and priorities of each project.

\begin{tabular}{|l|l|l|l|l|l|}
\hline Tochnology & $\begin{array}{l}\text { Data } \\
\text { rate }\end{array}$ & Frequency & Sensitivity & $\begin{array}{l}\text { Transmittor } \\
\text { power }\end{array}$ & $\begin{array}{l}\text { Link } \\
\text { budget }\end{array}$ \\
\hline Wavenis & $19 \mathrm{~kb} / \mathrm{s}$ & $900 \mathrm{MHz}$ & $-107 \mathrm{dBm}$ & $14 \mathrm{dBm}$ & $121 \mathrm{~dB}$ \\
\hline Zigbee & $250 \mathrm{~kb} / \mathrm{s}$ & $2400 \mathrm{MHz}$ & $-98 \mathrm{dBm}$ & $8 \mathrm{dBm}$ & $106 \mathrm{~dB}$ \\
\hline Bluetooth & $1 \mathrm{Mb} / \mathrm{s}$ & $2400 \mathrm{MHz}$ & $-85 \mathrm{dBm}$ & $7 \mathrm{dBm}$ & $92 \mathrm{~dB}$ \\
\hline Z-Wave & $40 \mathrm{~kb} / \mathrm{s}$ & $900 \mathrm{MHz}$ & $-101 \mathrm{dBm}$ & up to $0 \mathrm{dBm}$ & $101 \mathrm{~dB}$ \\
\hline DECT & $1 \mathrm{Mb} / \mathrm{s}$ & $1900 \mathrm{MHz}$ & $-98 \mathrm{dBm}$ & $25 \mathrm{dBm}$ & $123 \mathrm{~dB}$ \\
\hline
\end{tabular}

Figure 28. Source: https://www.unifore.net/images/products/104_data_zigbee_z_wave_dect.jpg.

The following overview compares several Technologies in terms of the Data rate and the range of the radio signals:

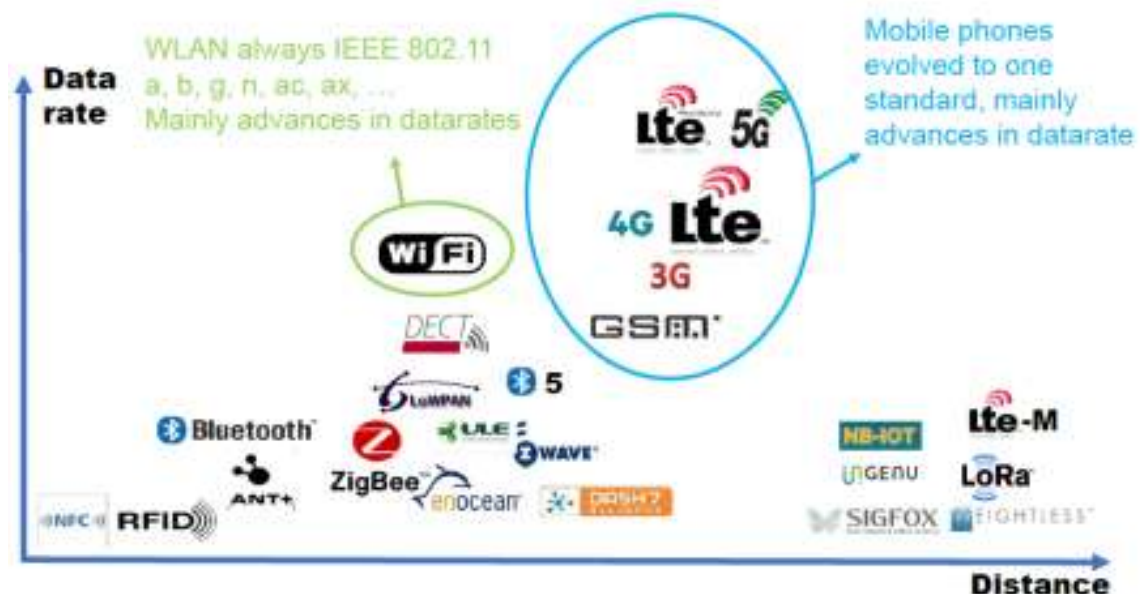

Figure 29. Comparison of technologies. Source: postscapes, grafical comparisson of IOT technologies.

These are only a few technical aspects that need to be considered and are usually defined by the hardware of the systems. Of course there are many other layers in the Software and API (Application Programming Interface) that scale the complexity even more, as you can see as an example for ZigBee in the following graphic.

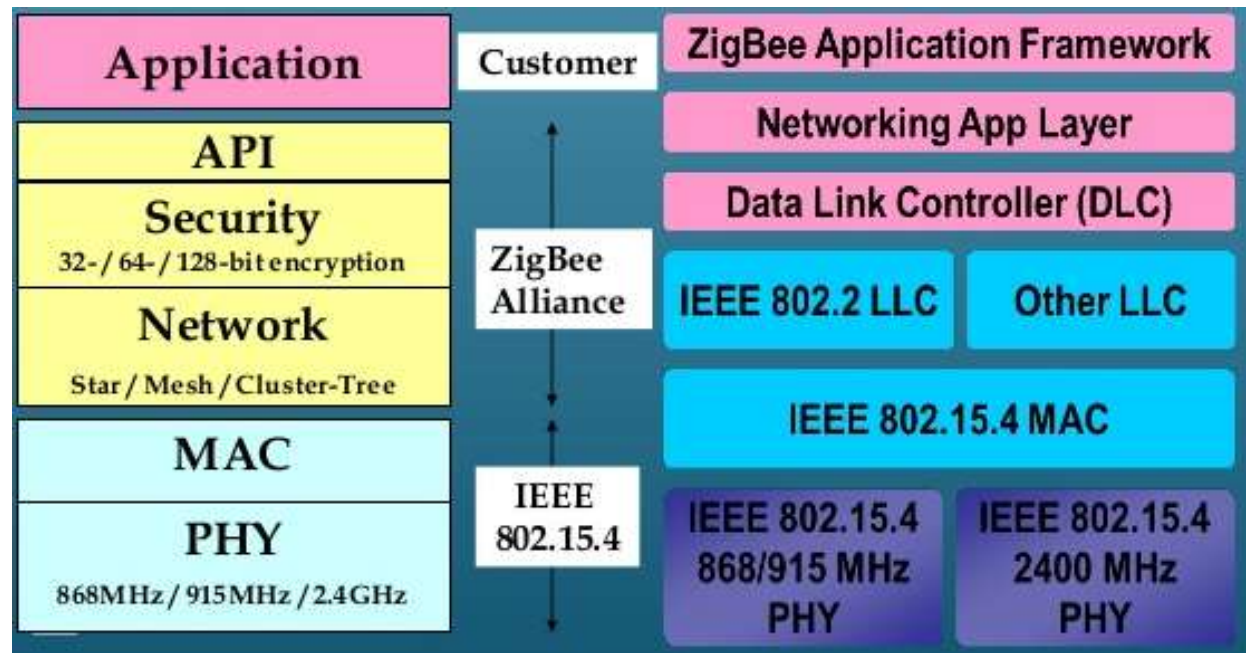

Figure 30. https://image.slidesharecdn.com/sunilcredit-150417231946-conversion-gate01/95/wireless-sensor-networksusing-zigbee-and-wifi-13-638.jpg?cb=1429313021. 
At the moment there are various ambitious stakeholders or alliances, who try to create standards based on their technologies or Applications. The loT Landscape of Matt Turck gives an idea of the current Situation concerning the technological Building Blocks, the horizontal Platforms and Enablers, and the vertical Application Fields like Personal, Home, Vehicles, Enterprises and Industrial Internet.

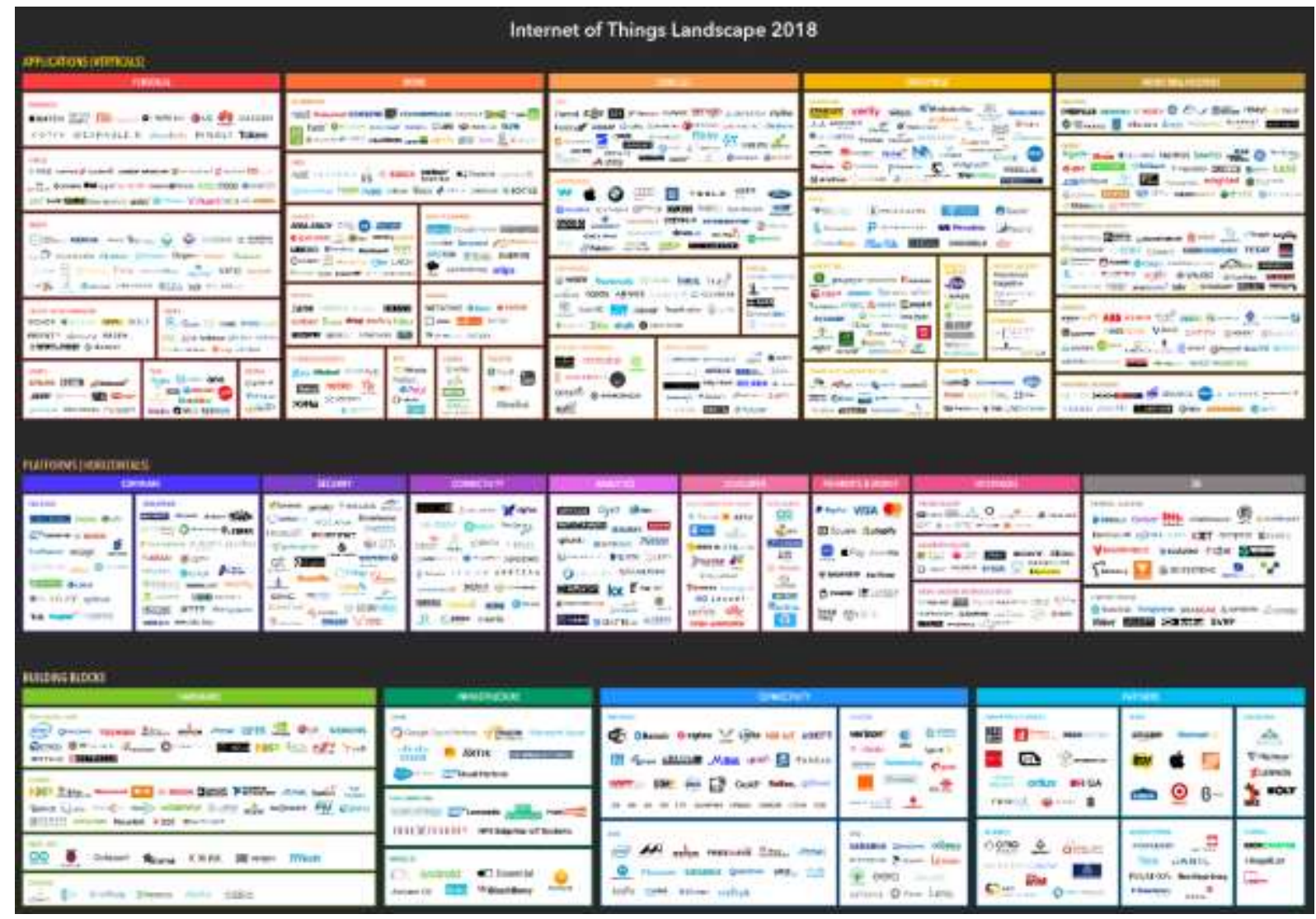

Figure 31. http://mattturck.com/wp-content/uploads/2018/02/2018_Matt_Turck_loT_Landscape_Final.png.

In terms of lighting and façade control systems, the "vertical" application home and the connectivity building block might be the most important fields, but as we are talking about a very agile and connected environment, there is a lot of possibilities in every one of them.

\section{AUTOMATION}

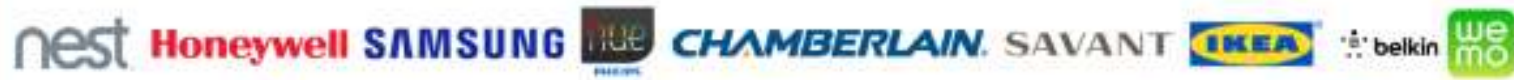

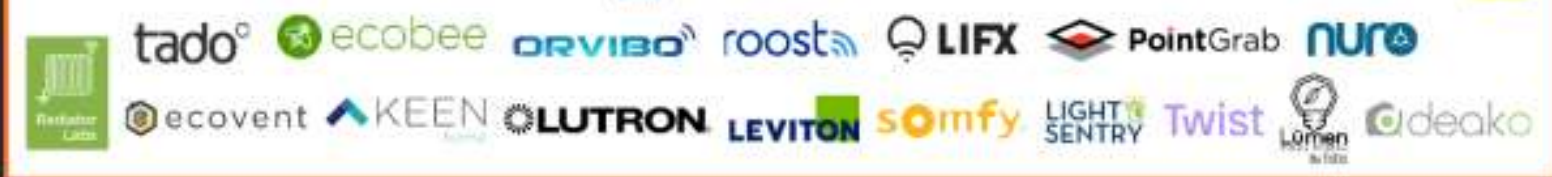

Figure 32. http://mattturck.com/wp-content/uploads/2018/02/2018_Matt_Turck_loT_Landscape_Final.png - Applications - (Verticals) Home Automation. 


\section{PROTOCOLS}

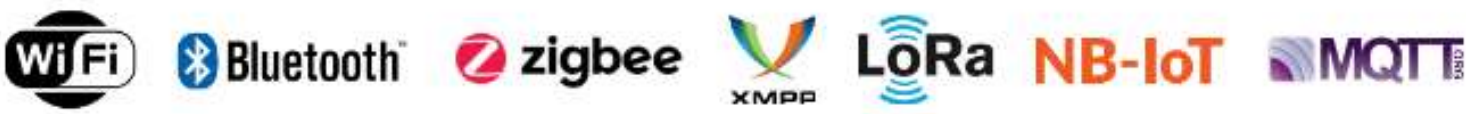

\section{N1 Towave EAMQP M-Bus MiWi X10 THREAD}

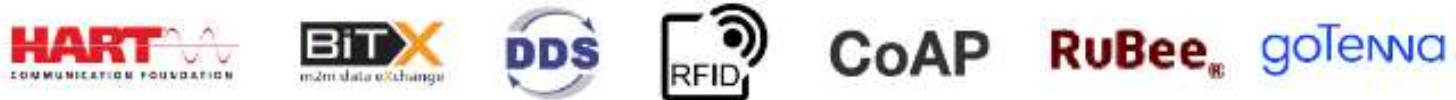

$2 \mathrm{G} 3 \mathrm{3} \quad 4 \mathrm{G}$ 5G LTE 6LoWPAN LPWAN LWM2M LTE-M V2X

Figure 33. http://mattturck.com/wp-content/uploads/2018/02/2018_Matt_Turck_loT_Landscape_Final.png - Buiding Blocks - Connectivity - Protocols.

In terms of Energy consumption the "EnOcean" technology stands out, as it has an energy harvesting approach, using electromagnetic, solar, and thermoelectric energy converters for the information transition.

WiFi and Wireless Wi-Fi Alliance offers two categories like Building and Smart Home where lighting or shading control systems can be certified to assure interoperability. At the moment the professional building sector is not using wireless LAN Solutions, due to factors like high costs of the communication modules and radiation exposure. The high data rate is usually not needed for sending and receiving control signals for lighting, heating or blinds. To interfere with other protocols like ZigBee, ZWave or LORA, as it is installed in any buildings all over the world and reachable by smartphones, tablets and computers.

\subsubsection{Bluetooth}

Bluetooth or BLE (Bluetooth Low Energy) has brought many "point to point" solutions, since the operation and the installation is very easy and efficient to do. Usually it can be done by the user himself, as it can be compared to the "installation" of a smart speaker or the connection of a car to a smart phone. The user is guided through the graphical user interface of an app and is able to control the lamp or to adjust settings like colour temperature and brightness. Since Bluetooth Mesh was brought to the market in 2017 there are more and more solutions allowing the control of bigger groups of luminaires. First BLE controlled shading systems are being brought to the market while this report is being written. Examples for BLE Products on the lighting \& shading market are xicato, casambi or frogblue. 


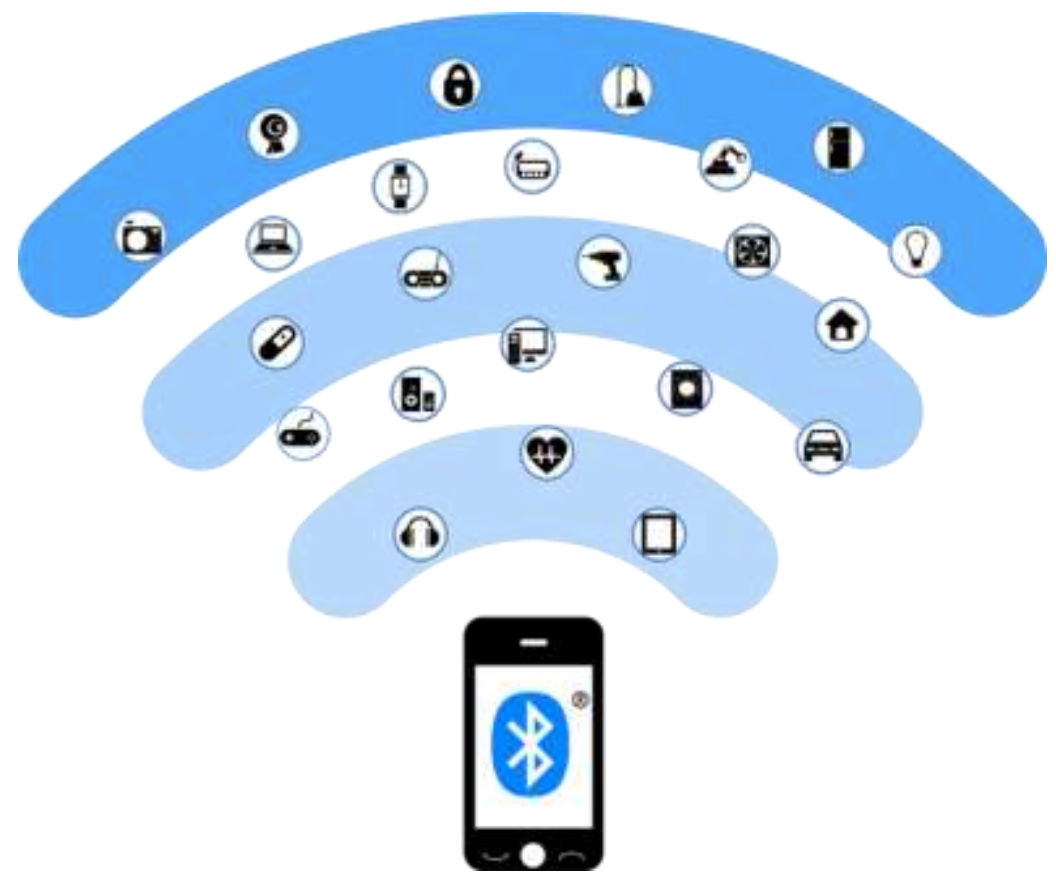

Figure 34. https://www.onsemi.com/site/images/loT-Graphic-Bluetooth-Connectivity.png.

\subsubsection{ZigBee}

The ZigBee Alliance was founded in 2002 and counts more than 230 companies. It is usually controlled via Gateways that are linked to a LAN/W-LAN. There are two profiles to interact with lighting. "Light link" offers plenty of functionality to control and adjust lighting installations. With "Home Automation" there is also the possibility to control lighting, but it also offers control of other components like shading, audio, security and heating systems. It has been implemented in many Drivers for LED Fixtures or bulbs and is also available for a small range of shutter controls. Since Philips (HUE). IKEA (Trädfri) and many other big companies are using ZigBee as a protocol, it has become one of the most important solutions in the wireless control market in Europe. It is also used for Smart Energy (smart gas meter, smart electricity meter) solutions. As ZigBee is an open source network, the Software can be adapted by the producers, which can lead to interoperability problems. At the moment there are 2.190 ZigBee certified products available on their website.

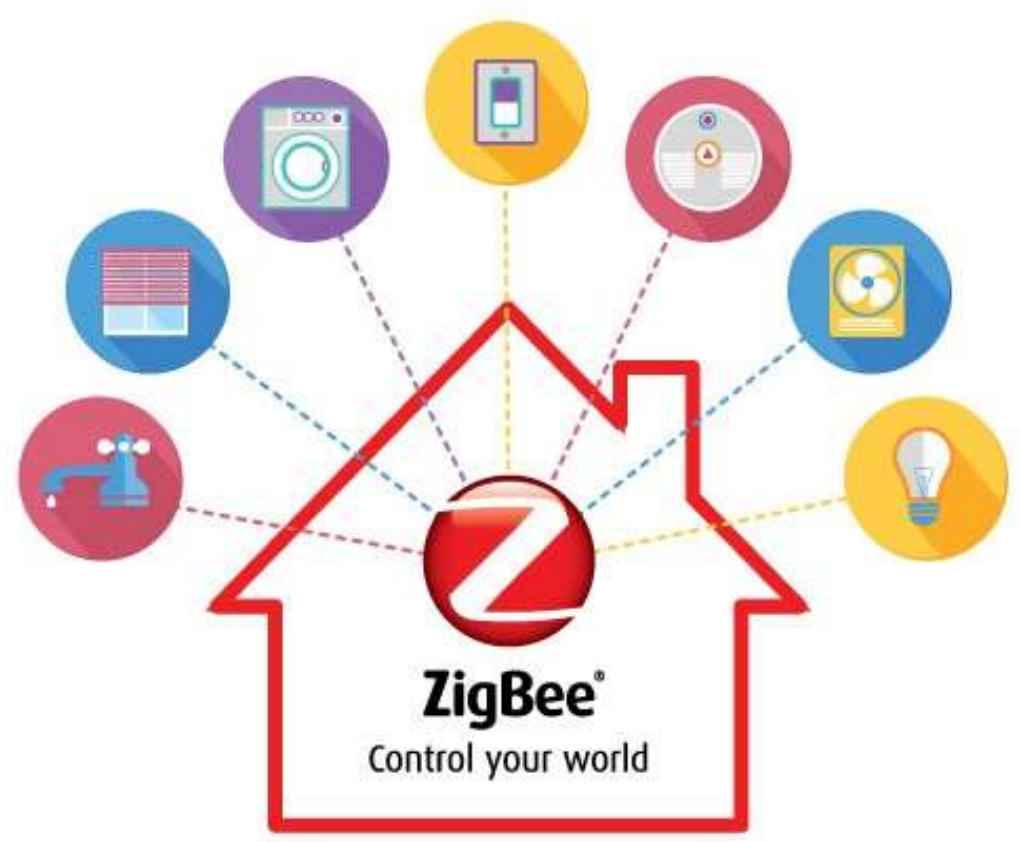

Figure 35. Source: ZigBeeAlliance. 


\subsubsection{Z-Wave}

Z-Wave was developed by two Danish engineers in 2001, first products came to marker in 2004. The z-Wave Alliance was founded in 2005. Today it has more than 600 members and is based in California. The main market is America, due to the radio frequencies, which are not available in European or Asian standards (between 850 and $950 \mathrm{MHz}$, while ZigBee is using $2.4 \mathrm{GHz}$ ). The main operation area is the smart home, the "z-Way" app enables end users to create their own smart home without knowledge of programming. All Z-Wave Products, use the same chip, which should ensure the interoperability of the products, anyhow changes and adaptations might be needed in the applications. At the moment there are more than 2400 certified products listed on the Z-Wave Alliance Website.

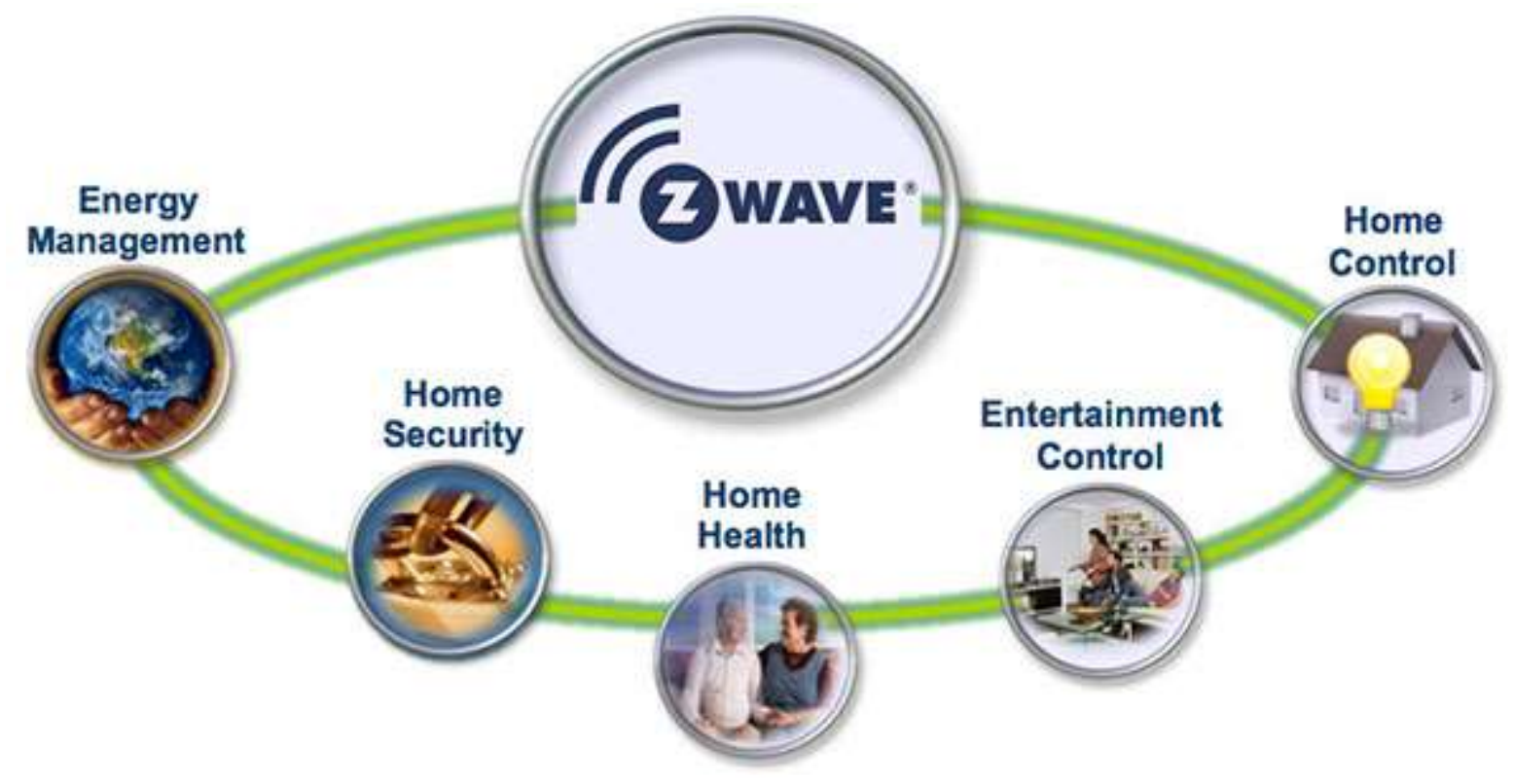

Figure 36. Source: ZWave-Alliance.

\subsubsection{EnOcean}

EnOcean is based on a low consumption and batteryless radio sensor technology. It is using "energy harvesting" solutions, to avoid batteries, creating the necessary amount of energy, to send control signals. The patented technology from 2001 was developed in Germany (Siemens Spin-off) and the EnOcean Alliance was found in 2008, which is now based in San Ramon, USA. It is also based on 868 to $928 \mathrm{MHz}$. Today there are 400 Companies joining the alliance and more than 1.500 products available. 


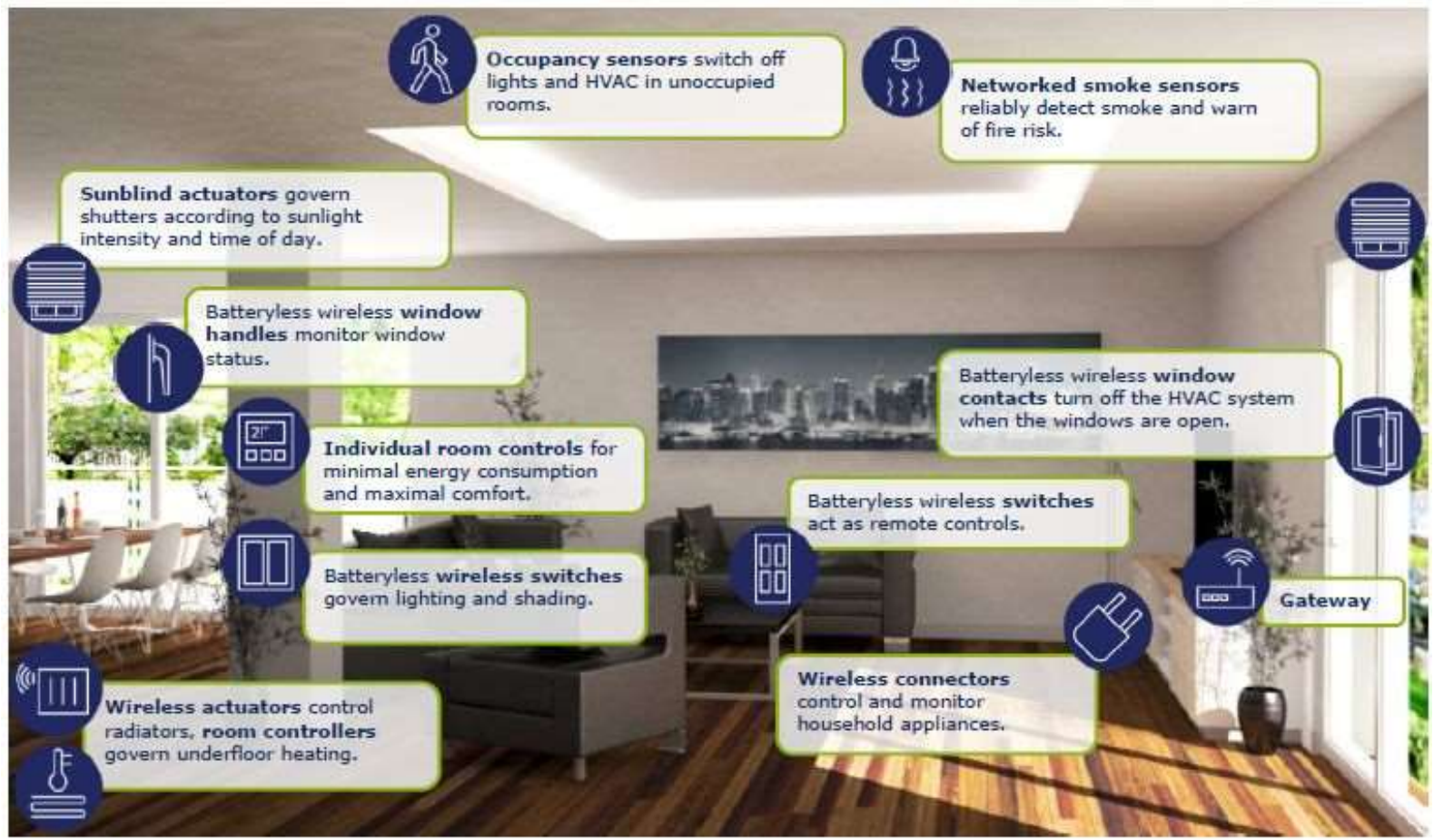

Figure 37. https://www.enocean-alliance.org/wp-content/uploads/2018/02/residential_EN.jpg.

\subsection{Pros and cons for the different protocols, from the user perspective}

There are a number of issues which are raised from the evolution of the control techniques. The interest for energy savings and improved level of service will depend of the way these techniques solve problems.

Here is a list of questions which the above review started to raise. And we would require extensive survey among professionals.

\section{How easy is the Installation of the technology?}

- How many pieces of hardware are needed?

- Is a special software (beside an app) needed?

- Is an electrician capable to install the system without an expert?

How easy is the commissioning of the system?

- Is a special tool needed (beside an app)?

- $\quad$ Are two persons needed?

- Is it pre-commissioned or is it done on site?

How easy is it to re-group a participant of a network?

- Is a special tool needed (beside an app)?

- Does it take more than three minutes?

- $\quad$ Can it be done by a novice?

How open is the system to other technologies than lighting?

- Is it open to other technologies thang lighting?

- Is it open to other protocols via a gateway?

- Is it interoperable with other technologies?

How future proof is the system?

- How long time has the system been on the market?

- How big is the market share?

- $\quad$ Are big companies involved?

How robust is the system?

- What happens in the case of a short power failure (1-10 Minutes)? 
- What happens if one of the components is not working anymore?

- What happens if a router is not working anymore (if needed)?

\section{How safe is the system?}

- Is the system permanently sending and receiving information?

- Is the system secured by a firewall or something similar?

- Is the system certified?

\section{How much energy is consumed by the system?}

- $\quad$ Does it raise the stand-by power consumption by more than $9,5 \mathrm{~W}$ per device?

- $\quad$ Does the system use batteries?

Other aspects related with wireless protocols

- $\quad$ Different frequency bands $(\mathrm{MHz})$

- Country specific regulation of the frequencies

- Access to radio chips with Dependencies to:

- Frequency band (MHZ)

- Transmitterpower $(\mathrm{dBm})$

- Data rate $(\mathrm{kb} / \mathrm{s})$

The different systems do usually not have compatible protocols, which makes it difficult to combine the different control systems or extend with an additional system.

\section{Conclusion: which strategy to develop?}

If we focus on the scope of the IEA Task 61, the principle is to identify best possible approach to deploy successful lighting and daylighting strategies, meaning strategies leading to A) reduction of energy use and B) to improve satisfaction of building occupants.

Objective A) is achieved mostly in allowing the system to operate in a smart way, providing electric light only when needed, and in the appropriate quantities

Objective B) is broader, since it suggest that controls should help to reduce discomfort (glare from windows, inappropriate exposure to entering sunlight), improve physiological well-being (adjust spectra of light according the time of the day and the needs), contribute to security (cybersecurity, intrusion).

We have identified other benefits associated to new control systems: flexibility (adaptability of changes in the use of buildings), simplification of installation, easier commissioning and simplified maintenance.

We have also identified needs for improvement: more standardization to compensate by the extreme diversity of systems. For example, the frequency bands of wireless protocols is one issue among others: The differences in frequency bands $(\mathrm{MHz})$ depend on country specific regulation of the frequencies.

Clearly, reduction of costs of systems is needed, since costs are often judged in excess in relation to the financial benefits during operation. But some costs are diminishing with mass production (for instance electric motors for shading). Control is often an option brought late in the design process, and then abandoned for reasons of costs. In residential buildings, market of automatic control for shading is booming: high gains in relation to costs, added value when selling the house/apartment.

This suggests that energy conservation cannot be the only objective for the promotion of lighting and daylighting controls. The energy benefits should be associated with other benefits in operation, to make the supply more attractive.

We have also shown that:

- State of the art is quite different in residential and non-residential buildings

- Occupants expect to possibly override the system when necessary.

- Commissioning task should not be underestimated, since the success of control system is judged by the right operation: providing light quantities and spectra in accordance to needs.

- Robustness has been described: increasing sophistication of control could lead to increasing the potential failures. Solution are proposed, with regular checks integrated in the software. 
- Acceptance by building occupants is an important aspect, suggesting to inform/communicate or even provide training. User interfaces will be discussed in section B4. 